Research Article

\title{
An Analysis of Loess Tunnel Failure and Its Mechanism
}

\author{
Shuai Shao, Shengjun Shao $\mathbb{D}$, Jun Li, and Bing Qiu \\ Department of Civil and Architecture Engineering, Xi'an University of Technology, No. 5 South Jinhua Rd., Xi'an 710048, China \\ Correspondence should be addressed to Shengjun Shao; sjshao@xaut.edu.cn
}

Received 14 December 2020; Revised 29 January 2021; Accepted 19 February 2021; Published 2 March 2021

Academic Editor: Jian Zhou

Copyright (c) 2021 Shuai Shao et al. This is an open access article distributed under the Creative Commons Attribution License, which permits unrestricted use, distribution, and reproduction in any medium, provided the original work is properly cited.

A series of changes of mechanical properties such as fracture development, relaxation, collapse deformation, and strength decreasing of the surrounding rock of loess tunnels occur due to shearing and immersing, and loess tunnels will be prone to engineering failures, including large deformation, fissure, ground collapse, landslide, and lining cracking, seriously threatening the construction and operation safety of tunnels. These problems are especially prominent for long-span loess tunnels. Based on the understanding of features in the construction and operation of the loess tunnel project and proceeding from the perspective of structural evolution of loess, distribution of the shear deformation zone, instability of the excavation face, and adverse effects of geological conditions, the predisposing factors of damage of the surrounding rock and the supporting structure of large-span loess tunnels, common types of failures, and their formation mechanisms are analyzed in this paper. According to the relationship between the evolution of the loess structure and the law of strength change, an improved Mohr-Coulomb elastic-plastic, tensioncompression-shear, constitutive model, considering the loess structural property, is established and applied in numerical calculation. The formation mechanism of different failures in the course of loess tunnel construction is revealed by numerical analysis, in which the structural property of loess, loess strata, geological conditions, and excavating and supporting actions are simulated by the numerical method. A reference is provided for the prevention and remediation of engineering failures of a loess tunnel.

\section{Introduction}

Generally, the loess ground is typically composed of four kinds of stratigraphic loess strata $Q_{1}, Q_{2}, Q_{3}$, and $Q_{4}$, respectively, defined as the early Pleistocene $\left(Q_{1}\right)$ loess, middle Pleistocene $\left(Q_{2}\right)$ loess, late Pleistocene $\left(Q_{3}\right)$ loess, and the recent accumulation $\left(Q_{4}\right)$ loess. There are distinct physical and mechanical geotechnical properties from bottom loess strata $Q_{1}$ to top loess strata $Q_{4}$. Loess is a multiphase porous medium with a special structure behavior. With the rapid development of the transportation infrastructure in China over the last few decades, many new tunnels have been constructed or are being constructed through regions with challenging geological conditions. Hundreds of tunnels with large cross sections have been constructed in the ground, such as in the loess in China. Unconsolidated loess [1] is sensitive to sliding upon wetting and being broken down due to its metastable structure [2]. Loess has a significant character of randomly open and loose particle with high porosity [3-8]. When a large-span tunnel or underground space is constructed in the loess ground, the mechanical effect of the loess surrounding a tunnel is weakened by shear damage of the soil structure, cracked and relaxed by deformation development, collapsed and deformed by the damage of immersion, and it is also influenced by certain geological conditions like collapsed caves, cracks, and landslides, which may lead to large deformation, lost stability, crown collapse, lining fracture, and other failures during the tunnel construction, posing a threat to the construction and safe operation of the tunnel.

With the development of the traffic infrastructure in loess areas, the span of loess tunnels is growing in space. The larger the span of a loess tunnel, the greater the potential for rock damage, lining structure deformation, and rock instability during tunnel construction and operation. Compared with medium-span and small-span tunnels, large-span tunnels have the following basic mechanical properties. First, after excavation, the range of disturbed surrounding 
rock and redistributed stress yield of the surrounding rock will become larger. Secondly, the deformation of the stratum above the arch will have a larger range of influence. Thirdly, the stability of the surrounding rock will decline notably. Therefore, the separating excavation and timely supporting are required to enhance the overall support structure of the whole section and control the development of surrounding rock deformation. The stress conditions concentrated at the arch foot requires a high-bearing capacity. When a largespan tunnel or underground space is constructed in the loess ground, the settlement deformation of the surrounding rock above the crown will increase, which often requires reinforcement and enhancement of the support. Tunnel excavation will bring about great relaxation and further development of the loess fracture. The surrounding rock stability of the large-span tunnel will be more vulnerable to the influencing factors such as engineering geological conditions (adverse geological conditions, stratigraphic structure, underground water, etc.), tunnel section (span, height, and ratio of height and span, etc.), and construction conditions (excavation methods, support techniques, support time, etc.). In engineering practice, due to differences in space and time, only one or several factors will play a dominant role, and appropriate measures need to be taken to minimize its impact on the surrounding rock. Therefore, analyzing the inducing factors of large-span loess tunnel damage is of particular importance.

Based on the existing research outcomes and practical experience, the author, through lots of researches, conducts a rather comprehensive analysis of common failures of largespan loess tunnel projects and their formation mechanisms, endeavoring to shed some light on the practice of loess tunnel design, construction, and operation.

\section{Analysis of Common Engineering Failures of the Loess Tunnel}

2.1. Tunnel Collapse due to Asymmetric Pressure. Due to the development of the gully cut, large terrain changes often give rise to asymmetric pressure on the entrance and exit of loess tunnels. Also, gully development will bring about shear deformation of the slope soil, weakening the soil structure and the resistance of the slope against landsides. Meanwhile, when the slope is steep, due to the poor rock surrounding the slope and its orthogonal cross section, on the one hand, the slope would face a rather large load of asymmetric pressure. On the other hand, the soil strength will decline as the shear further develops with the tunnel excavation. The slide and deformation of the slope together with the subsidence of the arch foot will dysfunction the supporting structure as a whole, at length, leading to the collapse of the upper stratum soil. As shown in Figure 1, a typical feature of this type of collapse is that it is dependent on the mountain and that the tunnel is subjected to high lateral pressure while the tunnel is only shallowly buried. This belongs to the collapse problem of the collapsible loess shallow tunnel under the effect of asymmetric pressure on the cross section slope. Damage often occurs on one side of the tunnel, which bears less stress than the other. In constructing this type of tunnel, the

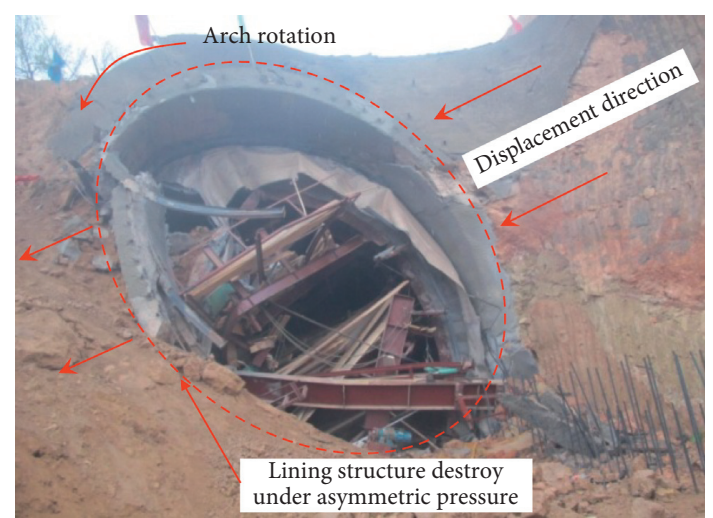

Figure 1: Tunnel collapsed under asymmetric.

principle of "short excavation, strong support, early closure should be followed, and its distribution of surrounding rock pressure should be readjusted, in a bid to prevent the tunnel ground shear slip and arch-end subsidence deformation caused by the development of rock surrounding deformation."

Loess tunnels built under asymmetric pressure require ground treatment when the surrounding rock above the vault drops or even when the entire loess stratum sinks, as there is no internal support, while landslides occur. A rather effective way is to reload and limit the development of the slope shear deformation and enhance the inside support of early lining. First, to reduce asymmetric pressure, the slope on the lining structure is excavated and filled to reload on two sides and avoid the stratum collapse and destroy the lining structure. Then, to support the collapsed body and limit the displacement of two sides of soil mass, the ground masonry rubble and the shotcrete protection are conducted. Last, the toe of the slope, which conducts the asymmetric pressure, is enhanced by the retaining wall to support the surrounding rock, so as to help the tunnel travel through the slope as shown in Figure 2. In the initial stage of excavation, an additional cross-wall against lateral unbalanced soil pressure on both sides should be set up in the early lining hole.

2.2. Ground Subsidence and Vault Collapse. The stability of the loess tunnel is closely related to the stability of support, lining structure, and excavation construction method. According to the surrounding rock classification and the span and height of the tunnel, an appropriate excavation method is selected to determine the reasonable support parameters. When the lining support structure and excavation construction method is designed, it is required to consider the surrounding rock composing of strata distribution of different loess with mechanical properties and the unfavorable geological conditions, including landslide, ground fissure, underground cave, and so on. When the design of lining support parameters and excavation construction methods are reasonable, it will not only be applied to the surrounding rock with better physical mechanical properties, symmetric surrounding rock pressure, and 


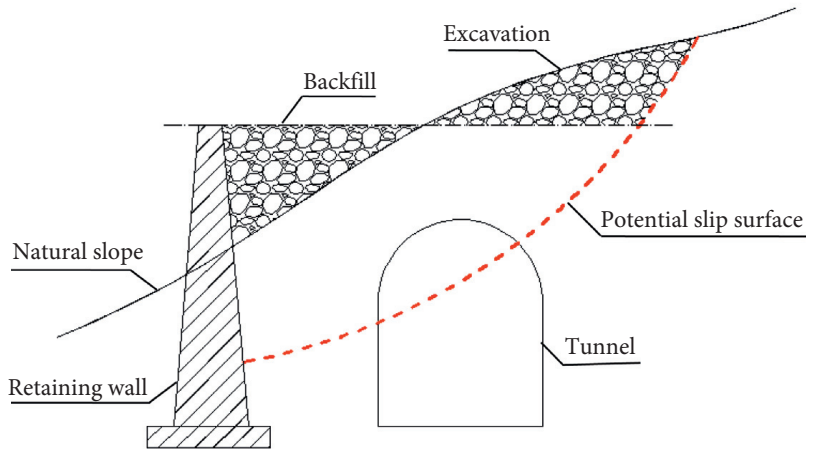

FIgURE 2: Schematic diagram of reloading method.

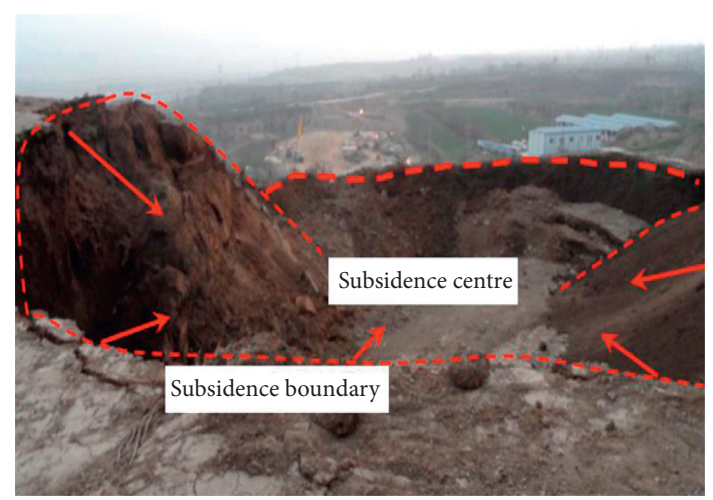

Figure 3: A wide range of surface subsidence. homogeneous soil but also with nonhomogeneous soil, development of underground cave, natural slope, and weak intercalation. It can not only adapt to the surrounding rock of loose loess but also denser old loess as well as different loess geological units. When the support structure is weak, the parameters of the tunnel section with largely different mechanical properties of surrounding rocks do not conform to the actual condition as reflected in actual construction, represented by insufficient bearing capacity of loess foundation under the arch foot of the lining structure, and the large settlement in skewback of collapsible loess, also leading to large development of settlement of the vault. Landslide is caused by destruction of the support structure and deformation development of the weak surrounding rock.

The entrance to the loess tunnel is located on a shallow buried loess slope and the excavation disturbance has caused large loess slides in the tunnel section. The loess was deposited on a gully developed by natural cutting of ancient landforms and mountains. The new loess (Q3 and Q4) deposited by different migration methods is thicker and is often buried at a shallow depth in the tunnel construction when the trench is first to cut in front of the tunnel inlet and then into the tunnel section. The foundation and the surrounding rock of the shallow-burying tunnel include new loess with loose soil quality, which settles under later construction. When the support structure is weaker, the lining structure is closed later, the foundation of structure skewback is gradually damaged, and compression settlement is increased, the settlement of the vault is large, and stability of the surrounding rock decreases with structural attenuation of excavation. Damage to the soil beneath the structure reduces the bearing capacity of the surrounding rock, and the collapse of the strata at the top of the vault causes the sidewalls and retaining walls to slide towards the tunnel excavation space. The damaging of soil mass on two sides of the tunnel shallowly imbedded in new loess lead to collapse of the overlaying layer above the arch, as shown in Figure 3. The stronger the characteristics of damage of soil mass on two sides of the tunnel, the greater is the sliding scale and the collapsing deformation of strata above the arch.

By putting up the horizontal support inside the lining structure and restricting the lateral shift of the lining structure, the stability of the surrounding rock and its lining structure is improved to control the settlement development of strata above the vault. By shortening the support time of the surrounding rock, reinforcing the skewback foundation, and timely closing of the lining structure, the stability of the surrounding rock and its lining structure is also enhanced. And, when the loose overlaying layer is thicker, support of the surrounding rock and the lining structure is enlarged to maintain stability.

The vertical fissure in the loess is developed, and it leads to the collapse of the overlaying soil mass on the tunnel arch. Besides, influent seepage of excess surface water forms a butterfly shaped concave, damaging the original structure of the soil, and thereby forming a vertical transfixing fissure plane on the outer side of the concave. The soil column in the concave applies pressure to support the structure of the vault. When the support structure on the vault cannot bear the vertical load of the overlaying soil column formed by fissure development, or when the concave develops to form the load of the soils column, the support structure is damaged to cause the vault collapsing, as shown in Figure 4.

Erection of grouted anchor pipes or advance support with pipe tops to restrain vault settlement, as a means of locking the anchor pipes of the lining structure and increasing anchorage, can effectively control vault settlement. By increasing the vertical support structure, decreasing the excavated section, timely closing of the lining structure, and enlarging the lining structure, the stability of the surrounding rock and the lining structure is improved significantly.

\subsection{Loess Flow Failure Caused by Excavation Face. Loess} possesses significant structural property. The original loess, $Q_{3}$ and upper $Q_{2}$, formed by natural wind-drift has low water content, and a large porosity ratio. When the structure has been disturbed by the displacement of excavation face, the structural strength of the unsaturated loess is lost with deformation developing, and the gas in the loess pores pressure is generated by compression. The soil particles that have broken the skeleton are in suspension due to air pressure and shear, with the unsaturated loess moving fluidly. The deformation of excavation face is caused by an increase of the shear stress and a decrease of the compression stress. As the shear deformation develops, soil structure is 


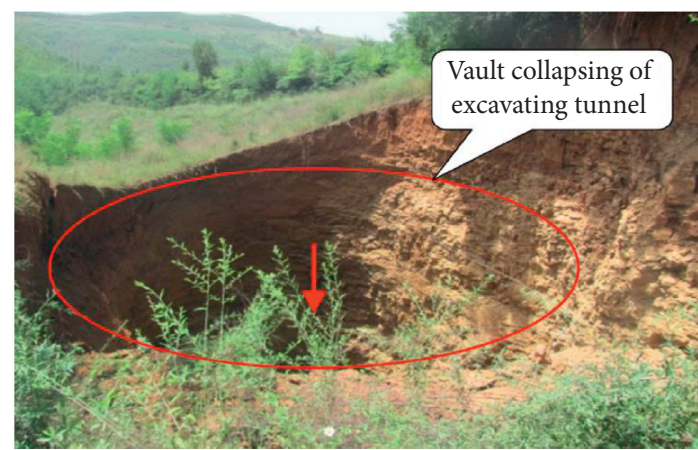

FIGURE 4: Vault collapsing of excavating tunnel.

damaged, excavation face destabilizes, the support effect for soil mass of excavation face is lost, and then the overlaying soil mass on the vault may collapse. The collapsed soil mass accelerates flowing of soil onto excavation face. The flow failure caused by excavation is as shown in Figure 5 .

After the loess with a large porosity ratio is immersed and saturated, the original structure of the loess $Q_{3}$ and upper $Q_{2}$ is destroyed largely by subjecting to collapsing deformation disturbance. When the deformation is caused by excavating, the loess structure will change further. If a soft plastic consistency or a fluid plastic consistency is reached, a debris flow will occur at the excavation face as shown in Figure 6 . The disturbance in the processing of excavation and construction can be decreased by setting anchor pipes on excavation face to soil mass.

2.4. Landslip of Tunnel Entrance Slope. On the one hand, the tunnel entrance locates at the natural loess slope formed by the cutting action of the gully development or depositing on the mountain slope. Accompanied by the soil mass deforming of the tunnel entrance excavation, the lateral laxation of the loess slope body leads to soil fissure development. On the other hand, the loess slope and the surrounding rock is subjected to disturbance caused by soil mass deformation in cutting the groove in the front of the tunnel entrance and excavating the tunnel entrance. Due to environmental scouring and erosion, unloading during the evolutionary development of natural slopes and the development of ground cracks along the slope direction, the native soil structure of the loess is constantly being destroyed during the accumulation of natural loess slopes. The fissure and the large pore can be developed into the cave by sloperunoff seeping into the ground, causing structural impair of immersion collapsibility, thereby lowering stability of the natural slope. In cutting the groove in the front of the tunnel entrance and the natural slope, the slope ratio of the overlaying slope increases, the shearing action in the overlaying slope increases, shear deformation development at the slope feet causes the traction of soils mass of potentially sliding the slope. The soil structural property in the area of shearing deformation in the overlaying slope further attenuates, and the stability of the overlaying slope at the entrance lowers again. When the portal excavation begins, the stress field of soil mass of the surrounding rock is

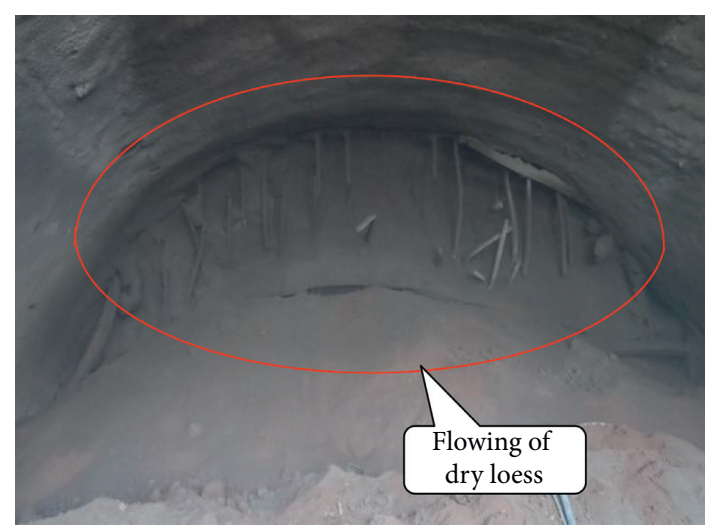

FIgURE 5: The dry loess flowing on excavation face.

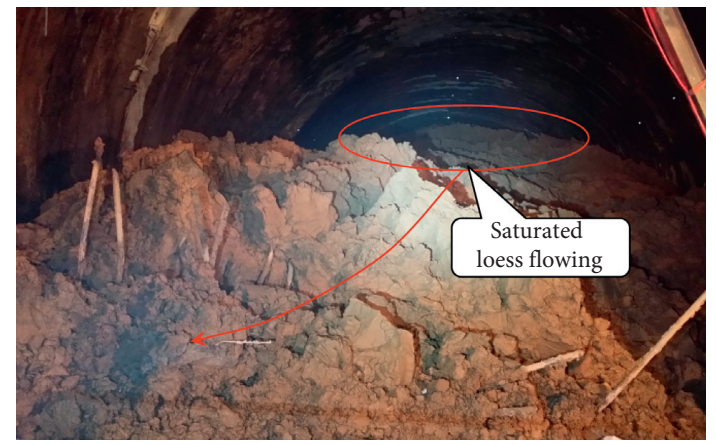

FIgURE 6: The saturated loess flowing on excavation face.

redistributed. The settlement of overlaying soil mass on the vault and shearing deformation of excavation face can enhance the loess mass breakage. When the compression stress is unloaded by excavating the space of the tunnel portal, the support action of soil mass at the slope foot is not enough to maintain the stability of the slope, or when the vault collapses and the lining structure is destroyed, the whole stability of slope may be lost, resulting in general sliding, as shown in Figure 7.

As a whole, engineering geologic condition of the natural loess slope is poor. In constructing the loess tunnel with a large-span section, the sliding damage is caused by the deformation developing under the cutting slope and unloading at the entrance, and the whole stability reduces in the evolutionary process of structural property distribution of soil mass. The destabilization of the overlaying slope also damages the supporting and lining structure at the entrance. The construction of the entering tunnel in the loess slope must follow the principles of grout pipe (grout pipe or long grout pipe shed), short excavation (controlling the excavation length, decreasing the disturbance of the surrounding rock), strong support (anchoring, reinforcing net, steel arch supporting, jetting concrete), quick closing (after excavating the short length and supporting the vault and the lateral wall, timely closing of the invert arch), prohibit damage caused by blasting (in constructing the tunnel, not utilizing the blasting excavation to lower disturbance of the surrounding rock), high-quality grout (in spacing of grouting pipe distribution, guaranteeing the grouting effect), frequently measure 


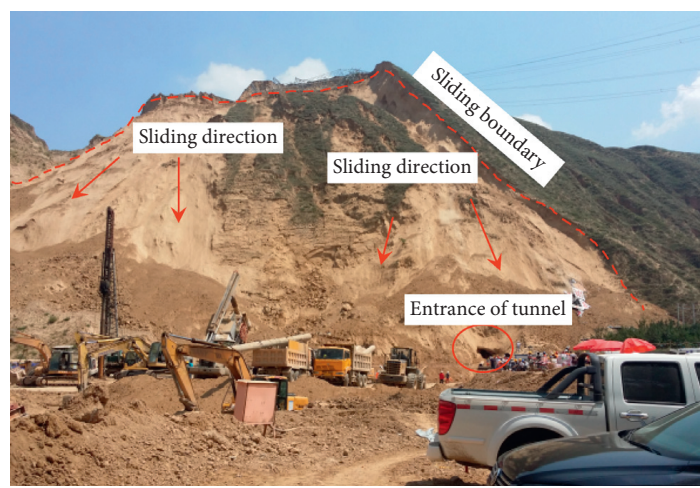

Figure 7: Front slope sliding.

(timely monitoring of the vault settlement, horizontal convergent deformation, surrounding rock pressure, law of support and lining structure, to facilitate timely adjustment of parameters of excavation outline, control over excavation and under excavation), form early closed ring (preliminary support closing as early as possible and forming a whole stable structure).

To avoid destabilization of the cutting slope in constructing the tunnel entrance, the excavation length of upper, middle, and lower steps are limited reasonably by considering the geologic conditions of the surrounding rock. The water proofing system on the loess plateau and mountain, and drainage system of the slope at the entrance should be constructed well before excavating the tunnel hole. According to the settlement of the vault, the supporting method, and stability of the surrounding rock, the long grout pipe shed is constructed, and the distance from the invert arch to heading face is limited reasonably. Because the displacement of excavation boundary in the loess tunnel occurs before an invert arch is not closed, the invert should be closed as early as possible, and the second lining structure should be timely constructed properly at the tunnel entrance. The selection of a reasonable excavation method can effectively control deformation of the surrounding rock, prevent cracking induced by different settlements, or even the landslide of the slope. In the process of excavation, the over excavation prohibited strictly softens the primary support effectively controlling the strata settlement on the vault.

\subsection{Ground Deformation and Fracture of the Loess Tunnel.} The bearing capacity of loess foundation is low, and the stability of the arch foot is bad. In the construction course, because the primary lining is not enough to support the loading of the surrounding rock, the settlement of soil mass on the tunnel vault is large. Along with the settlement of primary lining and soil mass on the vault, the cavity slump influences the safe work practices. The change and adjustment of stress yield in construction of the shallowly buried loess tunnel causes the displacement of loess mass. It is easy to lead to ground fissures, and has a great influence on geoenvironment and buildings, as shown in Figures 8 and 9 . This kind of deformation, developed from the vault to the surface, can form an uneven settlement groove with a certain range on the ground and in short duration. Thereby, the

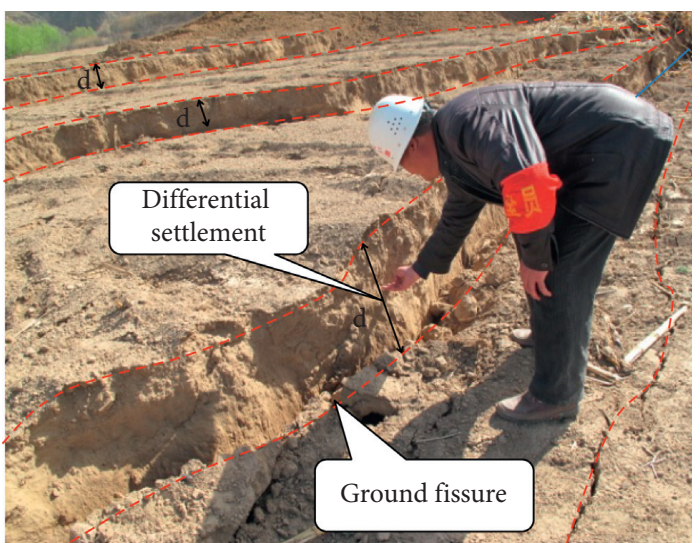

Figure 8: Ground fissure and differential settlement.

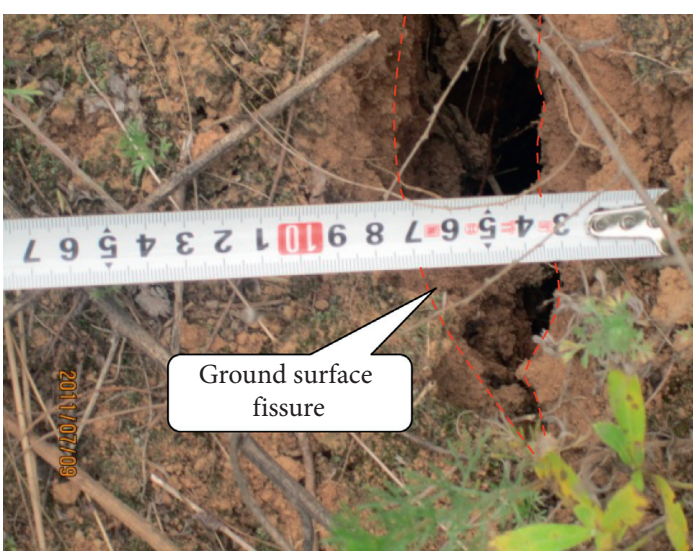

Figure 9: Ground surface fissure.

wedge body with a tendency toward sliding on upside loess of the excavated tunnel is developed to create the horizontal shift of two sides of the tunnel center, which points to the direction of the tunnel center line. There is a point with the largest horizontal shift on two sides of the tunnel center line, which is also located at the position of inflection point of surface vertical displacement.

Soil mass on vault settling toward excavated free face causes the sliding wedges of the upper loess on the tunnel extending toward the two sides. When tension stress or shear stress of sliding plane is greater than soil strength, the actual damage face is formed. When the sliding wedge moves downward and cracks the ground, the settlement on the vault becomes too large, and the lining structure destabilizes, resulting in landslides. After the formation of the upper sliding surface of the loess slope, the loess bodies on both sides of the tunnel squeeze each other. And the actual shear surface on the lower part is closed instead of opening shallow stratum. When the slide surface extends through to the surface, it is damaged due to tension stress equaling to soil tensile or shear strength, and a visible crack is formed due to good verticality of loess column.

According to a survey on surface crack of the constructed tunnels, the survey result of loess crack on the tunnel is as shown in Table 1. According to the ground crack 
caused by arch-wall construction method in new loess $Q_{3}$ and $Q_{4}$, the maximum buried depth of the tunnel is equal to $140 \mathrm{~m}$. The maximum tunnel buried depth for surface crack caused by double-side drift method in new loess and rubble strata is $35 \mathrm{~m}$. The maximum tunnel buried depth for surface crack caused by the construction method of arch drift and bench method in new loess, saturated loess, and mudstone is $120 \mathrm{~m}$. The buried depth for surface crack caused by doubleside drift method in new loess, saturated loess, and mudstone is $60 \mathrm{~m}$. The maximum buried depth of surface crack caused by three-bench and core soil method in old loess or middle drift and double-side drift method in $Q_{2}$ loess is $46 \mathrm{~m}$. The maximum buried depth of surface crack caused by double-side drift and core soil bench method in new loess and old loess is $91 \mathrm{~m}$. It is obvious that the tunnel buried depth for surface crack in new loess caused by arch drift and bench method is the largest; the tunnel buried depth for surface crack caused by arch drift and bench method in new loess, saturated loess, old loess, or mudstone is larger; the tunnel buried depth for surface crack caused by double-side and center core soil bench method in new loess and old loess is relatively large; the tunnel buried depth for surface crack caused by double-side drift method in new loess, saturated loess, old loess, or mudstone is relatively small; and the tunnel buried depth for surface crack caused by double-side drift method in new loess and rubble, or by three bench and core soil method, or middle drift and double-side drift method in $Q_{2}$ loess is the smallest.

Ground settlement and surface crack on the loess tunnel are easy to form in the low-lying land where the ground runoff yield comes together and the seepage flow in the strata channel appears. The surface water in the lowlying land seeps and continuously moves downward, and centralizes on vault of the lining structure, and continues to seep into tunnel foundation along the outer channel of the lateral wall of the lining structure. The humidification of overlaying soil mass on the vault causes its deformation, leading to further development of ground settlement and crack. The increased moisture in the foundations causes the lining structure to settle, which leads to cracks in the lining structure. The seepage channel is closed by cutting groove and backfilling surface to bare ground fissure. The rainfall seeping in low-lying lands is drained out by drainage passage to avoid loess collapse deformation by immerging.

2.6. Lining Structure Failure. Excavation method of tunnel, support form, and type of lining structure are closely related to the engineering geologic conditions. The engineering geologic condition of the surrounding rock is both the internal cause for tunnel damage and failure, and the selfsupport to avoid tunnel failure. If human factors are not considered, the roots for tunneling failures all can be found in engineering geologic conditions of the surrounding rock. Meanwhile, loess mechanical properties of the surrounding rock, such as compressibility, collapsibility, shear resistance, hydraulic properties, determine the engineering properties of loess tunnel [9].
$Q_{3}$ new loess has strong structural property; it is loose with a large porosity ratio and takes on vertical fissure development. Hence, it has significant collapsibility. In new loess strata, the deformation of the surrounding rock, belonging to brittle damage, is quickly released without early signs and occurs suddenly. It is easy to cause the vault collapse. Thus, the new loess deformation of the surrounding rock should be rigidly controlled by enhancing the preliminary support action. Generally, old loess with large buried depth is covered by new loess. The new loess and upper part $Q_{2}$ old loess underlying the tunnel are easy to generate, yield, and collapse deformation, which is caused after immersion, leading to nonuniform settlement of the lining structure. Meanwhile, it will increase earth pressure on the vault and wall waists, leading to larger deformation to the support structure as shown in Figures 10 and 11 . The deformation of old loess tunnel is a lengthy course. But when there is no support after excavation, too long a time to exposure excavation surface, or too long a time to construct the lining structure, large creep deformation of the surrounding rock is also easy to cause the vault collapse. Therefore, in constructing old loess tunnel, one should control surrounding rock deformation, reduce the plastic ring of the surrounding rock, and use strong preliminary support.

Loess pores and cavities are effective storage spaces and transport channels for groundwater, and loess is an important water-bearing medium for the strata. However, after tunnel excavation, the new joint fissure developed and lowintensity loess expands transfer passage of the ground water. When a tunnel passes through loess strata, on the one hand, the underwater in water-bearing area can seep along the crack between the lining structures and surrounding rock loess; on the other hand, the water in the low-lying land area on the surface penetrates quickly toward soil mass surrounding the tunnel along vertical fissure of loess. Loess immersion has severe influence on the property of the tunnel. The water function in soil mainly appears as softening effect, lubrication, denudation, weight gaining, and disaggregation. The result not only reduces intensity of damaged loess on vault and increases instability of wall rock but also causes water seepage into the tunnel and making construction more difficult [9]. The water function in the surrounding rock is a key object of research and attention in design and construction of the loess tunnel. It is needed to survey the constructing condition of the saturated loess tunnel, to measure the deformation of immersed nonsaturated loess on the vault, and the pressure increase of the surrounding rock, to determine support measures and control destabilization, and damage of the surrounding rock.

Loess with small moisture has higher stiffness and bearing capacity than large moisture. When the tunnel is further excavated, the loess is dampened by deformation development, and the water moves to loess on excavation face, leading to gradual weakening of soil strength, and the soil takes on soft mold state. After water content has reached a certain limit, sudden settlement and loess block sliding occur, making the excavation face lose self-stabilizing 
TABLE 1: Investigation of failures in loess tunnel.

\begin{tabular}{|c|c|c|c|c|c|c|}
\hline No. & Tunnel name & $\begin{array}{l}\text { Length } \\
(\mathrm{m})\end{array}$ & Construction method & $\begin{array}{l}\text { Depth } \\
(\mathrm{m})\end{array}$ & Failure & Soil \\
\hline 1 & $\begin{array}{l}\text { Xinzhuangling Tunnel in Chankou- } \\
\text { Liuhegou Highway }\end{array}$ & $\begin{array}{c}\text { Left } \\
1455 \\
\text { Right } \\
1422 \\
\end{array}$ & Arch drift method & $<120$ & Ground fissure & $\begin{array}{l}\text { New loess, } \\
\text { saturated loess, and } \\
\text { old loess }\end{array}$ \\
\hline 2 & $\begin{array}{c}\text { Pingjing Tunnel in Pingliang-Dingxi } \\
\text { Highway }\end{array}$ & $\begin{array}{l}\text { Left } \\
2600 \\
\text { Right } \\
2679\end{array}$ & $\begin{array}{l}\text { Double-side drift } \\
\text { method }\end{array}$ & 61 & Ground fissure & $\begin{array}{l}\text { New loess, } \\
\text { saturated loess, and } \\
\text { mudstone }\end{array}$ \\
\hline 3 & $\begin{array}{c}\text { Wolong Tunnel in Pingliang-Dingxi } \\
\text { Highway }\end{array}$ & $\begin{array}{c}\text { Left } \\
1402 \\
\text { Right } \\
1336\end{array}$ & Two-bench method & $20-120$ & Ground fissure & $\begin{array}{l}\text { New loess, } \\
\text { saturated loess, and } \\
\text { mudstone }\end{array}$ \\
\hline 4 & $\begin{array}{c}\text { Laojun Tunnel in Pingliang-Dingxi } \\
\text { Highway }\end{array}$ & $\begin{array}{l}\text { Left } \\
1180 \\
\text { Right } \\
1270\end{array}$ & Two-bench method & $20-120$ & Ground fissure & $\begin{array}{l}\text { New loess, } \\
\text { saturated loess, and } \\
\text { mudstone }\end{array}$ \\
\hline 5 & $\begin{array}{c}\text { Taiping Tunnel in Pingliang-Dingxi } \\
\text { Highway }\end{array}$ & - & Two-bench method & $20-120$ & Ground fissure & $\begin{array}{c}\text { New loess, } \\
\text { saturated loess, and } \\
\text { mudstone }\end{array}$ \\
\hline 6 & $\begin{array}{c}\text { Qinglan Tunnel in Pingliang-Dingxi } \\
\text { Highway }\end{array}$ & $\begin{array}{c}\text { Left } \\
1345 \\
\text { Right } \\
1415\end{array}$ & Two-bench method & $20-120$ & Ground fissure & $\begin{array}{l}\text { New loess, } \\
\text { saturated loess, and } \\
\text { old loess }\end{array}$ \\
\hline 7 & Baojiahe Tunnel & 590 & - & - & $\begin{array}{c}\text { Cave in, surface } \\
\text { collapse pit }\end{array}$ & $\begin{array}{c}\text { New loess and old } \\
\text { loess }\end{array}$ \\
\hline 8 & $\begin{array}{l}\text { A tunnel along the second main canal of the } \\
\text { Dadong river to the Qiwangchuan Region } \\
\text { Irrigation Project }\end{array}$ & 134 & $\begin{array}{l}\text { Single side-drift } \\
\text { method }\end{array}$ & $33-36$ & $\begin{array}{l}\text { Surface settlement, } \\
\text { crack }\end{array}$ & New loess \\
\hline 9 & Dayoushan Tunnel in Xiguojing Highway & $\begin{array}{l}\text { Left } \\
2553 \\
\text { Right } \\
2528\end{array}$ & $\begin{array}{l}\text { Two-bench and core } \\
\text { soil methods }\end{array}$ & $7-23$ & $\begin{array}{l}\text { Ground fissure, } \\
\text { lining crack }\end{array}$ & New loess \\
\hline 10 & $\begin{array}{l}\text { Caomaoshan Tunnel in Zhangjiakou- } \\
\text { Chengde Highway }\end{array}$ & 1557 & $\begin{array}{l}\text { Double side drift } \\
\text { method }\end{array}$ & 35 & $\begin{array}{l}\text { Ground fissure } \\
\text { and lining crack }\end{array}$ & $\begin{array}{l}\text { New loess and } \\
\text { sandy pebble }\end{array}$ \\
\hline 11 & $\begin{array}{c}\text { Yanjialing Tunnel in Qixian-Linfen } \\
\text { Highway }\end{array}$ & $\begin{array}{l}\text { Left } 676 \\
\text { Right } \\
556\end{array}$ & $\begin{array}{l}\text { Arch drift and core soil } \\
\text { method }\end{array}$ & - & $\begin{array}{l}\text { Ground fissure } \\
\text { and vault collapse }\end{array}$ & Old loess \\
\hline 12 & Lishi Tunnel of Fenliu Expressway & 180 & $\begin{array}{l}\text { Middle drift and } \\
\text { double-side drift } \\
\text { method }\end{array}$ & $3-46$ & None & Old loess \\
\hline 13 & $\begin{array}{c}\text { Liujiaping No. } 4 \text { Tunnel in Wubaoxian- } \\
\text { Zizhou Highway }\end{array}$ & $\begin{array}{c}\text { Left } \\
1914 \\
\text { Right } \\
1865\end{array}$ & $\begin{array}{l}\text { Two-bench and core } \\
\text { soil method }\end{array}$ & - & Ground fissure & $\begin{array}{l}\text { New loess and old } \\
\text { loess }\end{array}$ \\
\hline 14 & $\begin{array}{l}\text { Hancun Tunnel of irrigation project by } \\
\text { pumping the yellow river }\end{array}$ & 1275 & $\begin{array}{l}\text { Single side-drift } \\
\text { method }\end{array}$ & $10-11$ & None & $\begin{array}{l}\text { New loess, } \\
\text { Old loess }\end{array}$ \\
\hline 15 & Ciwan Tunnel in Jingbian-Ansai Highway & 465 & $\begin{array}{l}\text { Double side drift and } \\
\text { core soil bench method }\end{array}$ & $17-91$ & Large deformation & $\begin{array}{c}\text { New loess and old } \\
\text { loess }\end{array}$ \\
\hline 16 & $\begin{array}{c}\text { Yanjiagou Tunnel in Wubaoxian-Zizhou } \\
\text { Highway }\end{array}$ & $\begin{array}{c}\text { Left } 815 \\
\text { Right } \\
667\end{array}$ & $\begin{array}{l}\text { Two-bench method and } \\
\text { fan-shaped support }\end{array}$ & $<81$ & Ground fissure & $\begin{array}{l}\text { New loess and old } \\
\text { loess }\end{array}$ \\
\hline 17 & Baojiahe Tunnel in Yan'an City & 590 & Arch drift method & $10-140$ & $\begin{array}{l}\text { Vault collapse and } \\
\text { ground cave }\end{array}$ & New loess \\
\hline
\end{tabular}

Loess strata: $Q_{1}, Q_{2}, Q_{3}$, and $Q 4$; new loess: $Q 3$ and $Q 4$; old loess: $Q_{1}$ and $Q_{2}$. 


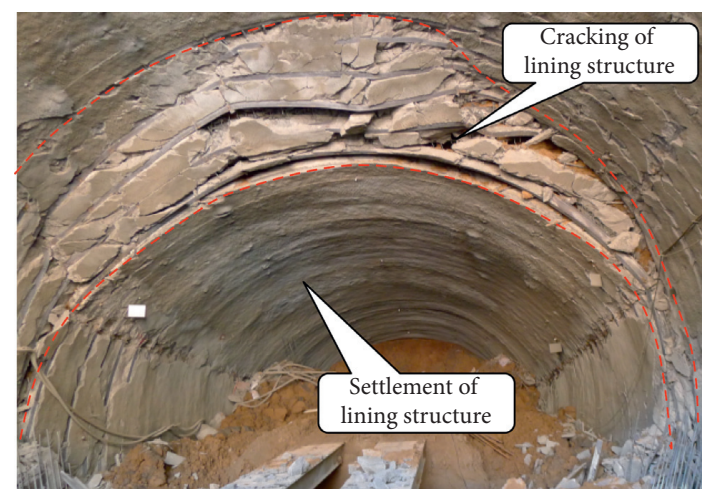

Figure 10: Cracking and settlement of the preliminary lining structure.

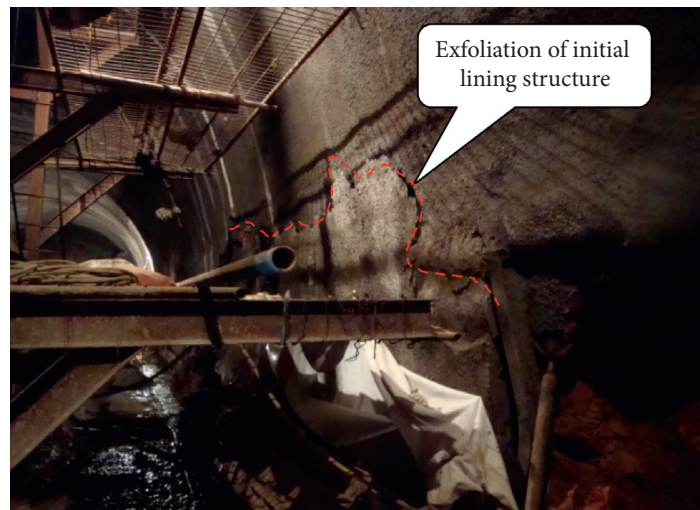

FIGURE 11: Exfoliation of the preliminary lining structure.

capacity rapidly. Especially after the immersed loess at skewback takes on the flow mold state, the bearing capacity is obviously inadequate, leading to settlement of the arch feet, and the preliminary shotcrete lining suddenly cracks, and steel grids severely flex and deform. If this is left untreated for long, ground fissures will appear and trend to further development. If the arch structure on the vault cannot meet to support the pressure of the surrounding rock, the overlaying strata will become loose rapidly. And when the loess foundation is sheared under self-weight or additional load and self-weight, soil structure will be damaged rapidly, and bearing capacity rapidly declines, making the surrounding rock disturbed by excavation rapidly lose self-stabilization capacity. While collapse and deformation develop, the lining structure can crack or even be damaged. If support measure fails to meet requirements on controlling surrounding rock deformation and applied load on the arch structure, sliding and vault collapsing up to surface is easy to occur.

Even after permanent lining structure is constructed, additional settlement produced by loess immersion and an increase in surrounding rock pressure will also cause too large additional stress of lining structure to avoid the structure crack. The longitudinal crack on inverted arch is as shown in Figure 12. The inhomogeneous settlement between tunnel foundation center of inverted arch and arch

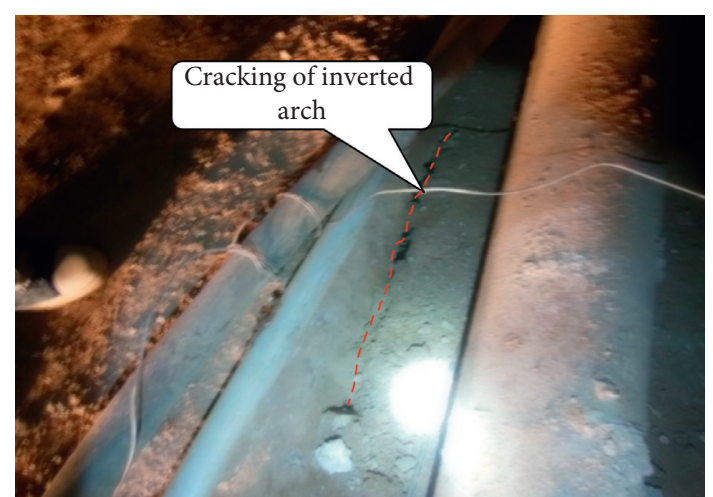

FIGURE 12: Cracking of the inverted arch.

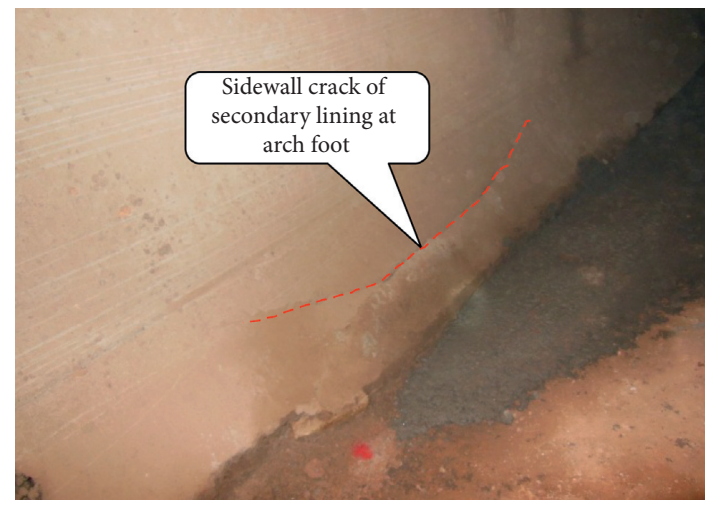

FIGURE 13: Crack of secondary lining at arch springing.

feet makes inverted arch produce tension stress, which is greater than tensile strength of concrete and induces inverted arch cracking. The sidewall cracking of secondary lining structure along longitudinal direction on arch foot, on which outside earth pressure acted and reduce the support force of inverted arch, is as shown in Figure 13. The obvious settlement difference between sidewall on arch foot and inverted arch leads to shear damage of the foundation. After the loess outside sidewall is immersed, the lateral earth pressure increases, the concrete on the inner side of tunnel is tensioned, causing crack along the longitudinal direction, as shown in Figure 14. The transverse crack caused by different settlements in the longitudinal direction is as shown in Figure 15. Because of unloading fissure developed and asymmetric earth pressure of tunnel entrance in the slope, the difference of foundation settlement is large. When the difference of foundation settlement is significant along longitudinal direction of the tunnel, a transverse crack is created. Even transfixing crack is formed on inverted arch, the sidewall, and the vault arch. The ground water can infiltrate into foundation along a transversal crack to aggravate nonuniform settlement in the entrance tunnel.

The geological hazards caused by tunnel excavation are summarized as follows: (1) the ground cracks, vault collapses and ground collapse holes, landslides in new loess, saturated loess, and other strata; (2) the collapse cave, 


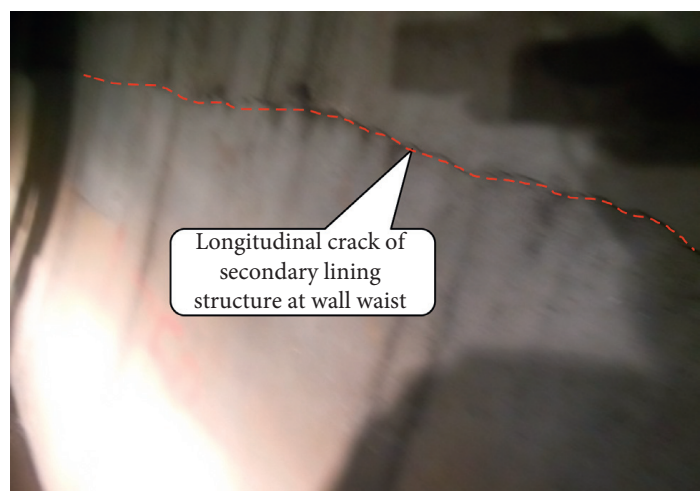

FIGURE 14: Longitudinal crack of secondary lining structure at wall waist.

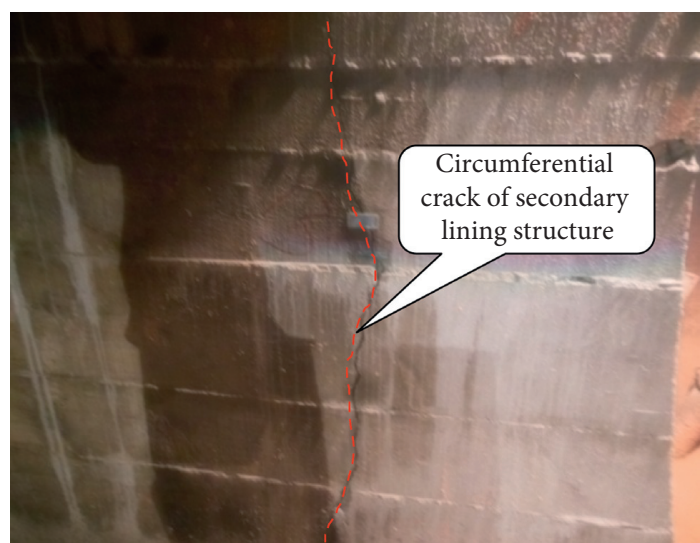

FIgURE 15: Circumferential crack of secondary lining structure.

surface collapse pit, or large deformation in the new and old loess strata; (3) the surface settlement, ground fissure, lining crack or vault collapse and ground collapse cave in the new loess stratum; and (4) the ground fissure and vault collapse in the old loess stratum. These geological hazards are described in Table 1.

\section{Numerical Analysis of Evolution Mechanism of Loess Tunnel Failure}

3.1. Model and Calculation Parameters. The formation process and mechanism of loess tunnel failures caused by the adverse geological conditions is numerically analyzed by using FLAC ${ }^{3 \mathrm{D}}$, a finite difference program. In the software of FLAC $^{3 \mathrm{D}}$, Mohr-Coulomb constitutive model is an ideal elastic-plastic constitutive model in which the failure surface described in principal stress space is the yield surface of soil. This constitutive model does not consider the progressive failure process of soil structure; that is, it does not consider the attenuation regularity of shear strength during the structural soil failure. However, the unsaturated loess is a typical structural soil, and the changes of its structural attenuation directly affect the shear strength and deformation stability of loess in the process of disturbance of tunnel

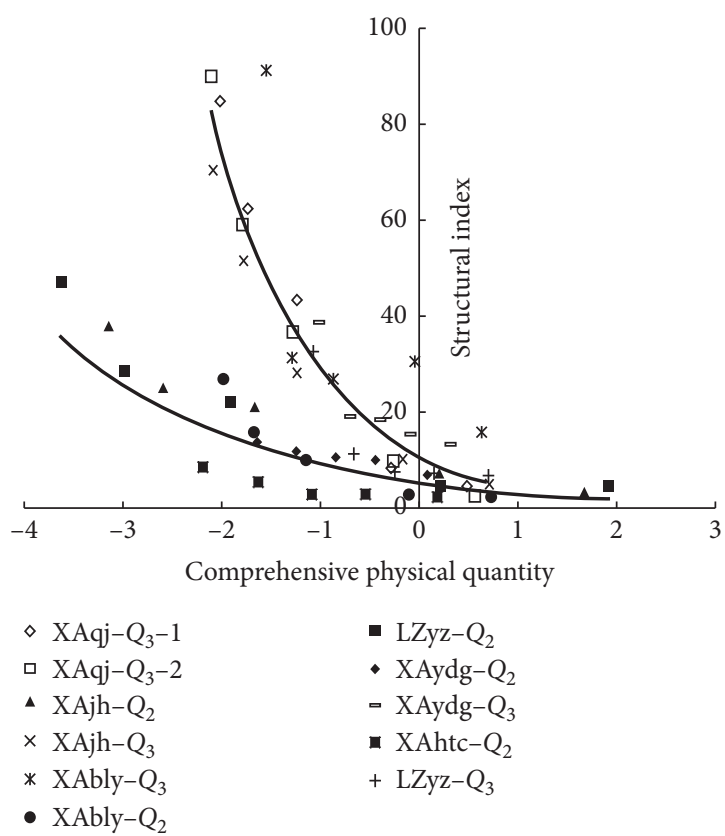

Figure 16: Relationship between the structural index of loess and the comprehensive physical quantity [11].

construction. Therefore, Mohr-Coulomb elastic-plastic model is modified by considering the change of soil structure with plastic deformation under loading and humidifying. The method is a reference to linear law between sensitivity variation ratio and damage strain variation [10], considering the structural change caused by the development of plastic deformation under loading (Figure 16). Based on the relationship between initial structural index and comprehensive physical quality $[1,11]$, the structural change caused by humidifying is also considered. Then, the relationship between structural index and shear strength index of loess is established. Thus, the constitutive model is modified, and it is embedded in FLAC ${ }^{3 \mathrm{D}}$ [12] with FISH command to simulate and analyze the evolution mechanism of the loess tunnel failures.

Establishment process of Mohr-Coulomb yield function, which considers structural attenuation is as follows:

(1) Loess structural property includes the fabric characteristics and banding characteristics (crystalline salt, clay cementation, bound water, and shrinkage film), which are closely related to the existence of unsaturated pore water. The quantitative index of structure (structural index) can be determined by the product of immersion sensitivity and perturbation sensitivity. The greater the immersion sensitivity and disturbance sensitivity, the greater the structural index of soil, and the structure is much stronger. Otherwise, the structure is smaller. At the same time, the immersion sensitivity reflects the sensitive degree of loess losing strength under immerging water, while the disturbance sensitivity reflects the sensitive degree of particle and pore arranging homogeneously after remolding the original state of soil. The greater the 
structural index, the greater the strength change of soil subjected to immersion and disturbance is, and the potential danger to the project is much greater. As for collapsible loess, the strength decreases greatly after encountering water, and it has great influence on the soil structure. It shows that flooding is the dominant factor causing the soil structure to be destroyed. Similar to disturbance sensitivity of undisturbed soil, the product of disturbance sensitivity of unsaturated loess and that of immersion sensitivity can be defined as generalized sensitivity [11]. The relationship between the generalized sensitivity and the comprehensive physical quality of loess in different sedimentary ages is as shown in literature [1], where generalized sensitivity expression of loess has been established in different sedimentary ages.

$$
\begin{aligned}
& Q_{3} \text { loess : } s=10.7 e^{-0.98 \cdot\left(I_{L} \rho_{d} /\left(\rho_{w} e_{0}\right)\right)}+1, \\
& Q_{2} \text { loess : } s=6.75 e^{-0.52 \cdot\left(I_{L} \rho_{d} /\left(\rho_{w} e_{0}\right)\right)}+1 .
\end{aligned}
$$

In equations (1) and (2), $s=$ structural index, $I_{L}=$ liquidity index, $\rho_{d}=$ dry density $\left(\mathrm{g} / \mathrm{cm}^{3}\right)$, $\rho_{w}=$ water density $\left(\mathrm{g} / \mathrm{cm}^{3}\right)$, and $e_{0}=$ void ratio.

When a soil structure is damaged in compression shear, the plastic volume and shear strain are assumed to have the same effect. The damage strain determined by the following equation:

$$
\varepsilon_{D}=\sqrt{\varepsilon_{v}^{p 2}+\varepsilon_{s}^{p^{2}}} .
$$

In the equation (3), $\varepsilon_{D}=$ plastic comprehensive strain, $\varepsilon_{v}^{p}=$ plastic volumetric strain, and $\varepsilon_{s}^{p}=$ plastic shear strain.

According to the linear law between sensitivity variation ratio and damage strain variation [9], the relationship between generalized sensitivity and plastic strain is also in accordance with the formula:

$$
\frac{\dot{s}}{s}=\chi \dot{\varepsilon}_{D}
$$

In the equation (4), $\chi=$ constant.

The generalized sensitivity of naturally deposited unsaturated loess is always greater than 1 , so formula above can be rewritten as:

$$
\frac{\dot{s}}{s-1}=\chi \dot{\varepsilon}_{D} .
$$

The integral of (5) can be as follows:

$$
s=\left(s_{0}-1\right) e^{-\chi \varepsilon_{D}}+1 .
$$

In the equation, $s_{0}$ refers to the initial generalized sensitivity under loading and humidifying.

(2) It has been shown that the cohesion of soil decreases with the attenuation of generalized sensitivity of the structure, and the friction angle of soil is not changed basically with the variation of structural generalized sensitivity, as shown in Figure 17. Therefore, the relationship between the shear strength index of loess and the generalized sensitivity of structure can be established as follows:

$$
\tau=c(s)+\sigma \tan \phi
$$

In the equation (7), $\tau=$ shear strength, $c(s)=$ cohesion with the change of structural index, $\sigma=$ the normal stress on shear plane, and $\varphi=$ inner friction angle.

The relationship between cohesion and generalized sensitivity can be expressed as:

$$
c=c(s)=F \cdot e^{(-(s / I))}+J,
$$

where, $F, I$, and $J$ are related parameters of structural strength, respectively. $F=-118, I=8, J=102$.

The relation between tensile strength index and structural parameters of loess is shown in Figure 18 and expressed as

$$
\sigma_{t}=K c(s)=K\left(F \cdot e^{(s / I)}+J\right),
$$

where $K$ refers to tensile strength index, $K=0.5$.

Considering that cohesion and tensile strength are affected by the decrease of generalized sensitivity, the corrected Mohr-Coulomb strength failure surface is shown in Figure 19.

Based on the engineering of large-span loess highway tunnel in the loess plateau region, the tunnel site belongs to low mountain erosion landform, and there are thick quaternary late Pleistocene Aeolian loess (Q3eol) loess layer. Maximum depth of the tunnel is about $50 \mathrm{~m}$, and the tunnel section is horseshoe. Its height is $12 \mathrm{~m}$ and span is $17 \mathrm{~m}$.

In order to reflect a variety of engineering failures, loess damage and fractures caused by excavation, vault collapsing, and mud flowing on excavated face in the process of excavation and slope sliding as well as other issues were simulated and analyzed, respectively. Two kinds of models were set up, as shown in Figures 20 and 21 . A model mainly simulates the collapsed loess cave buried in different formations, which is caused by loess collapsing in the low-lying land; another model simulates the entrance tunnel at the overlaying slope.

In these models, the solid element is adopted in the stratum. The preliminary lining structure of the tunnel adopts shell element, and the secondary lining structure of the tunnel and the filled concrete in inverted arch are linear elastic solid elements. Initial stress is calculated by Mohr-Coulomb elasticplastic constitutive model, and tunnel excavation is conducted by simulating the three-bench method, as shown in Figure 22. The Mohr-Coulomb elastic-plastic model, in which strength parameters of surrounding rock soils decrease with structural attenuation, is applied in the process of excavation simulation. When the soil thickness on the vault is small and the generalized sensitivity is attenuated to 1 , it is destroyed, and the residual 


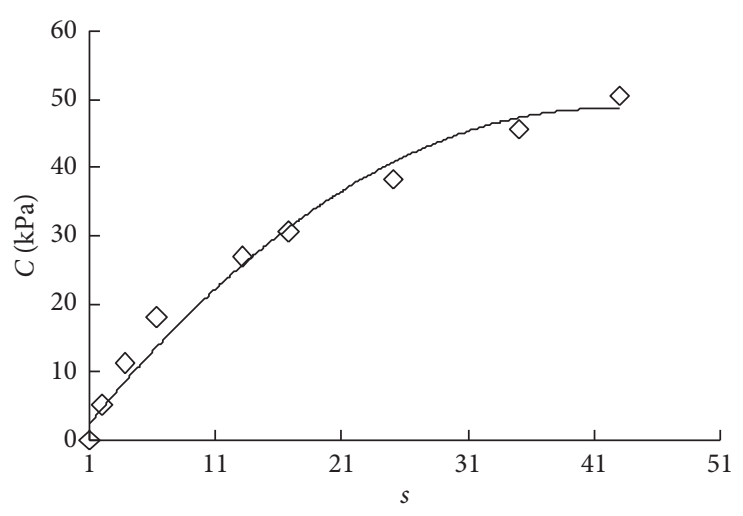

(a)

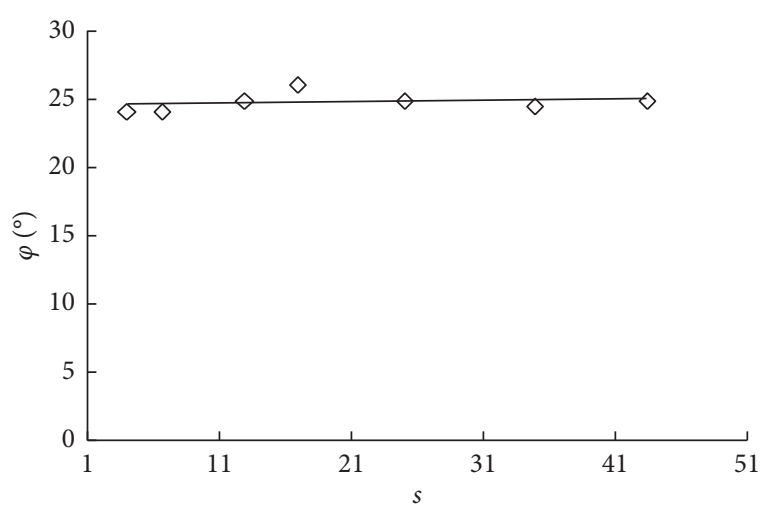

(b)

FIGURE 17: Relationship between structure parameter and cohesion. (a) Variation of cohesion with generalized sensitivity; (b) Variation of internal friction angle with generalized sensitivity.

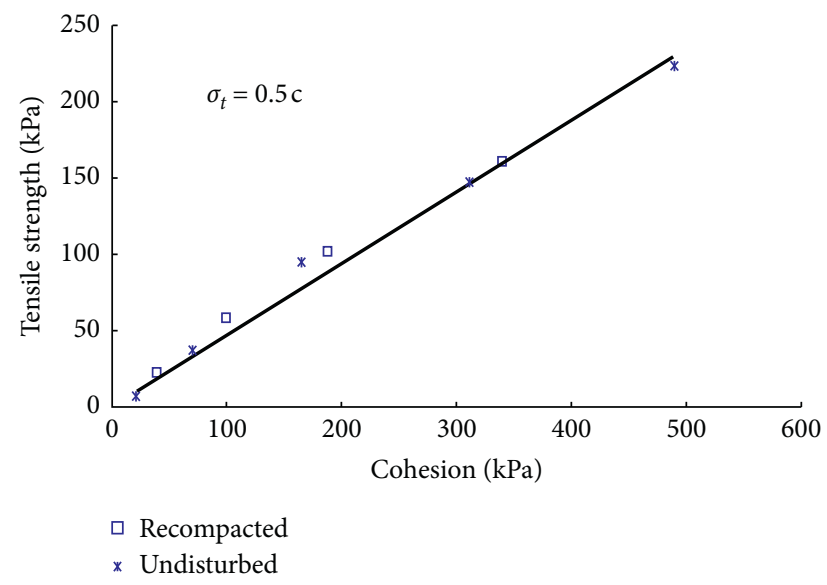

FIGURE 18: Relationship between cohesion and tensile strength.

strength is zero. The calculation parameters are as shown in Table 2.

\subsection{Analysis of Surrounding Rock Damage and Fracture} Evolution. For the subsidence deformation or vault collapse caused by tunnel excavation at different depths, tunnel model A set in free horizontal ground with soils strata is applied to calculate the initial stress field, which is analyzed by simulating the excavation face, and the preliminary and secondary lining structure. After tunnel excavation, the distribution of generalized sensitivity and plastic zone of the surrounding rock of loess tunnel with different buried depths are shown in Figures 23 and 24 , respectively. They reflect the structural damage of surrounding rock of loess tunnels with different depths.

As can be seen from Figures 23 and 24, during the excavation of the tunnel, the structure failure zone (generalized sensitivity attenuated to 1) of the surrounding rock of $Q_{3}$ loess varies from center zone and two sides on the vault to two sides on arch shoulders, and increasing with the buried depth, the soil structure damaging curve surface forms gradually. After the damage of the soil structure, there is basically no residual strength. When the buried depth is less than $30 \mathrm{~m}$, the structure damage surface of the surrounding rock develops almost vertically toward the ground (the generalized sensitivity equaling to 1 in the white and blue area nephogram, which shows that the original structure of soil has been destroyed). The surrounding rock pressure is the soil-column pressure on the vault, and there is shear fracture on the surface above the tunnel. Due to the formation loess, a tensile plastic zone (red zone in plastic nephogram) is formed in a certain area of both sides of the ground, and cracks appear in the soil layer. From the shear crack to the tension crack at different locations, a table similar to that shown in Figure 8 has been formed. Under the condition of large buried depth $(\geq 30 \mathrm{~m})$, shear plastic zone develops outward the arch shoulder, and outward inclining angle is about 30 degrees. The soil column between soil structure damaging curve surfaces still mainly acts on the vault, on which vertically shearing is developed at arch shoulder. Shear plastic zone expanding to the outer side of shoulders still reaches to the surface, and plastic domain on vault develops obviously. At the same time, the pressure on the surrounding 


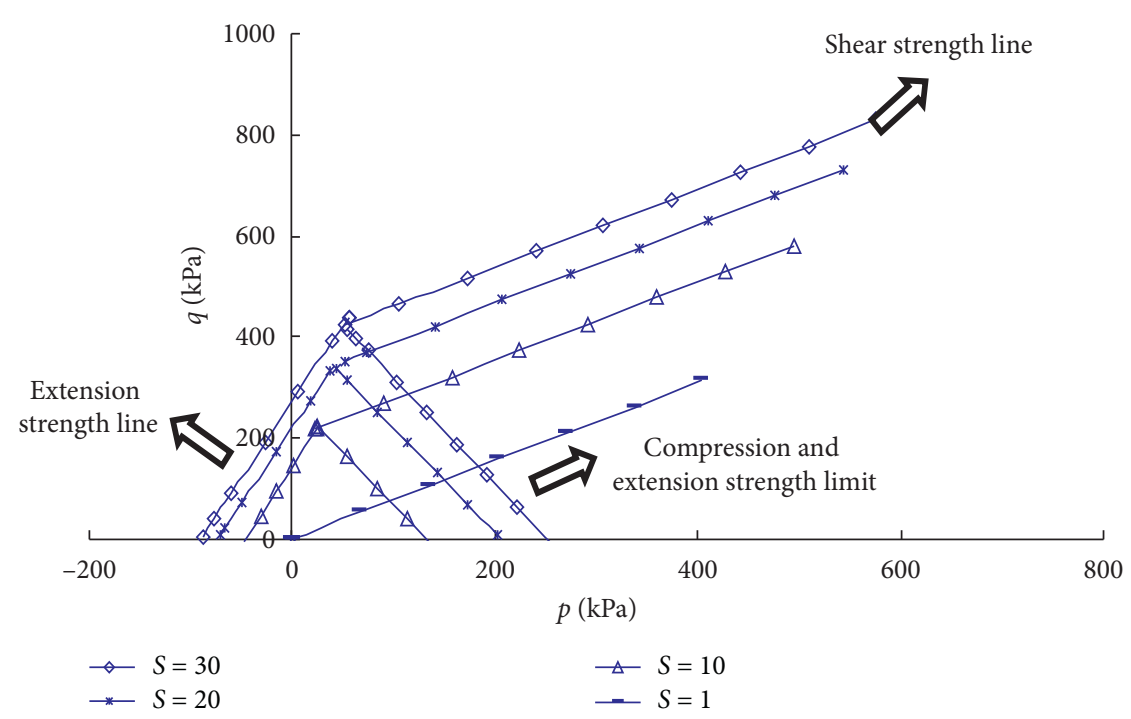

FIgure 19: Modified Mohr-Coulomb failure plane.

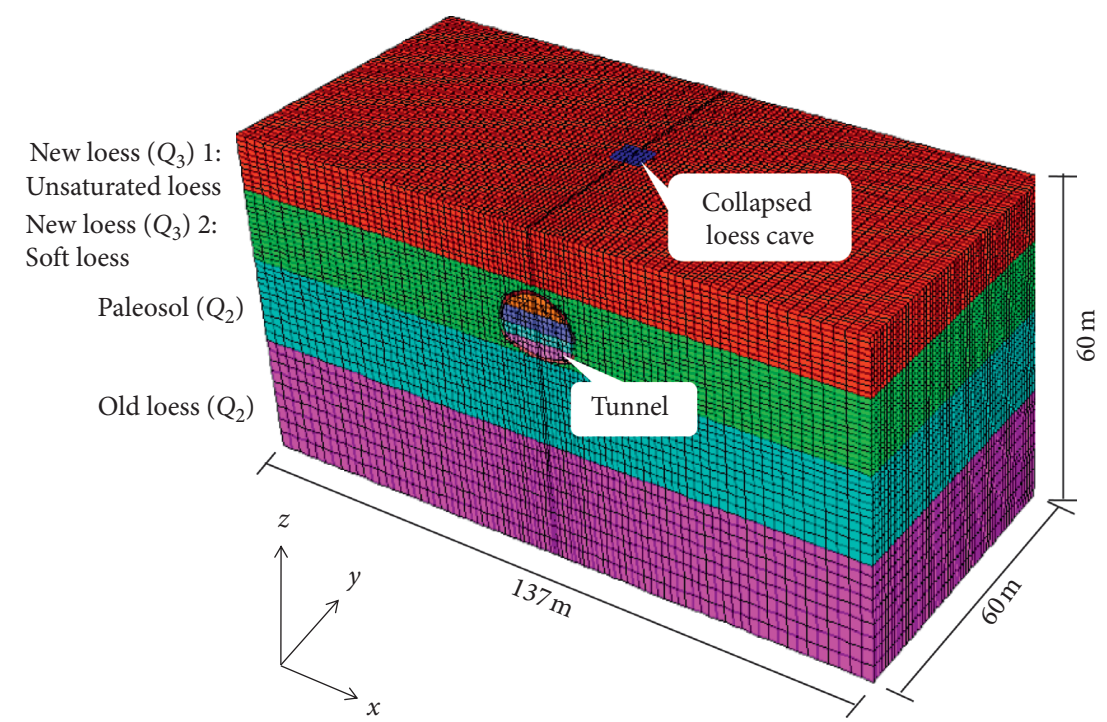

Figure 20: Computation model A.

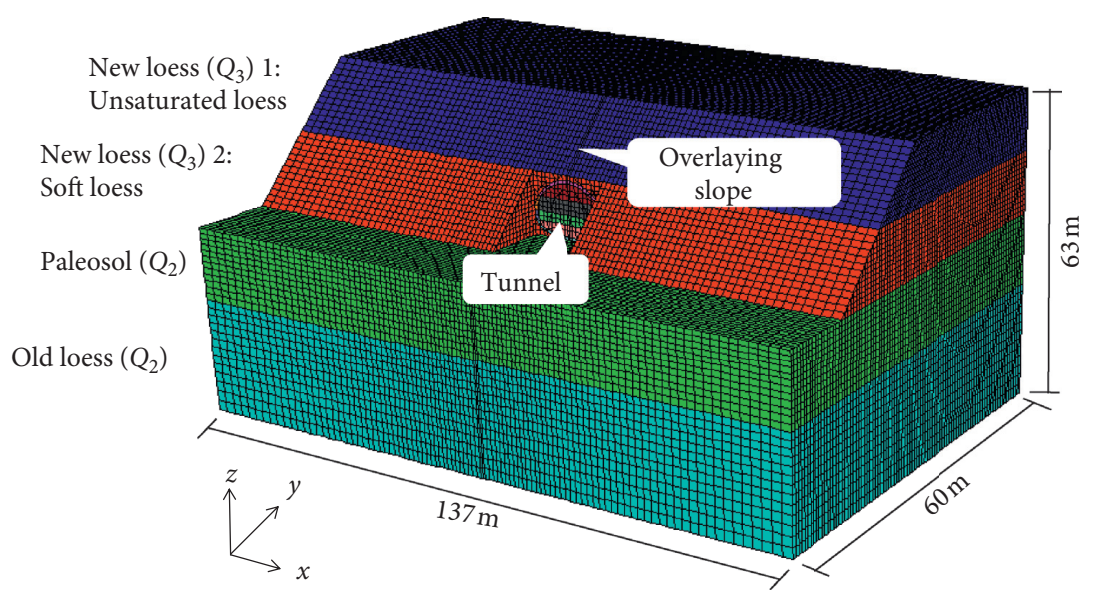

Figure 21: Computation model B. 


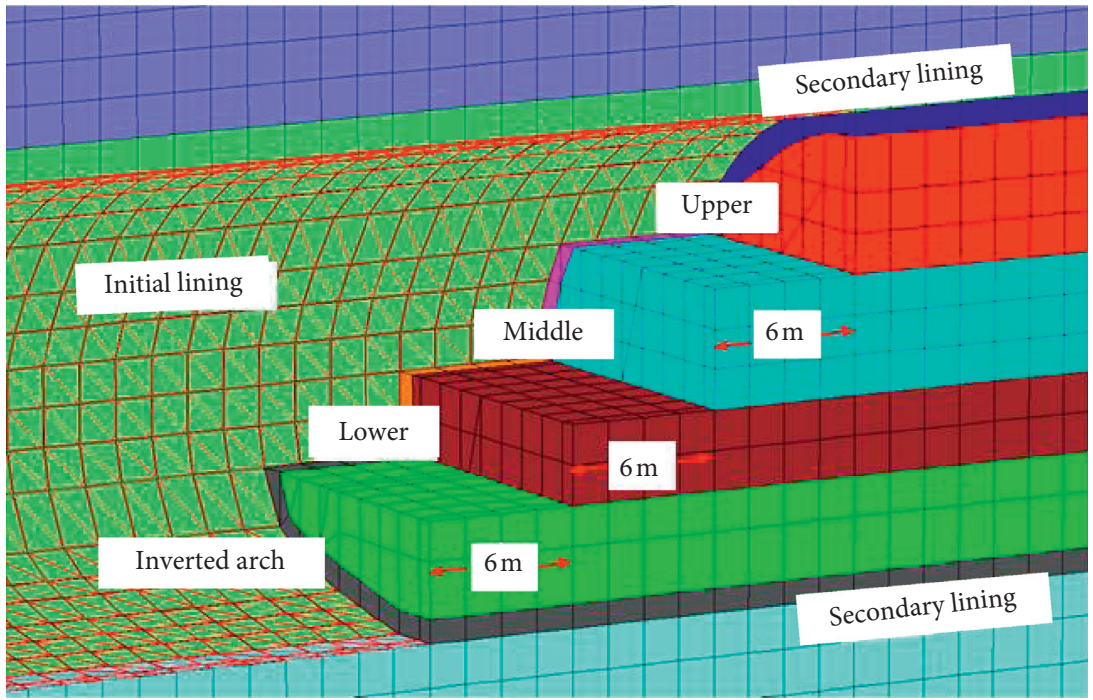

FIGURE 22: Simulation of three-bench method excavation.

TABLE 2: Parameters of numerical calculation.

\begin{tabular}{|c|c|c|c|c|c|c|c|}
\hline Group name & $\begin{array}{c}\text { Unit weight } \gamma \\
\left(\mathrm{kN} / \mathrm{m}^{3}\right)\end{array}$ & $\begin{array}{l}\text { Soil thickness } \\
(\mathrm{m})\end{array}$ & $\begin{array}{c}\text { Compression } \\
\text { modulus } E_{\mathrm{s}}(\mathrm{MPa})\end{array}$ & $\begin{array}{c}\text { Elastic modulus } \\
E(\mathrm{GPa}) \\
\end{array}$ & $\begin{array}{c}\text { Poisson } \\
\text { ratio } \mu \\
\end{array}$ & $\begin{array}{c}\text { Initial cohesion } \\
\quad C_{0}(\mathrm{kPa}) \\
\end{array}$ & $\begin{array}{c}\text { Friction } \\
\text { angle } \varphi\left(^{\circ}\right)\end{array}$ \\
\hline $\begin{array}{l}\text { Unsaturated loess } \\
Q_{3}\end{array}$ & 1450 & 10 & 16 & - & 0.32 & 25 & 20 \\
\hline Soft loess $Q_{3}$ & 1500 & 13 & 23 & - & 0.31 & 30 & 21 \\
\hline Paleosol $Q_{2}$ & 1700 & 15 & 26 & - & 0.3 & 30 & 23 \\
\hline Old loess $Q_{2}$ & 1800 & 22 & 31 & - & 0.3 & 30 & 25 \\
\hline $\begin{array}{l}\text { Collapsed loess } \\
\text { cave }\end{array}$ & 1450 & 10 & 8 & - & 0.32 & 2 & 15 \\
\hline $\begin{array}{l}\text { Saturated } \\
\text { disturbance loess }\end{array}$ & 1500 & 13 & 18.4 & - & 0.31 & 3 & 21 \\
\hline Initial lining & 2500 & - & - & 28 & 0.2 & - & - \\
\hline Secondary lining & 2500 & - & - & 32.5 & 0.17 & - & - \\
\hline Inverted arch & 2500 & - & - & 20 & 0.17 & - & - \\
\hline
\end{tabular}

rock increases due to the expansion of the shear plastic zone on the arch where the tilt occurs. The shear plastic zone is neither the pressure of the soil column with two vertical shear plastic zones at the shoulder of the arch nor the pressure of the collapsed soil acting within the shear plastic zone tilted outwards. Developed shear zone leaning outward inhibits the tensile stress distribution of the shallow soil. Crack development in surface tensile plastic zone reduces significantly, and the location distribution is far from the tunnel centerline. Under the condition of buried depth of 40-50 m, outer inclining angle of shear band at shoulders gradually increases from 30 degrees to 45 degrees, and plastic domain of shear band leaning outward develops through the surface. Plastic region on the vault is obvious, and there appears obvious failure zone of sliding collapse soil mass. The surrounding rock pressure is mainly the effect of weight of sliding collapse soil mass within shear zone, and balanced by supporting of lining structure. There is no surface tension plastic zone responding to obvious cracks.
3.3. Evolution Analysis of Vault Collapsing. At the center of the tunnel axis of model A, a cylindrical body with $3 \mathrm{~m}$ diameter is set to simulate the effect of collapsed loess cave on the stability of the surrounding rock during the tunnel excavation. The depth of the tunnel is $10 \mathrm{~m}$, and the cylindrical body representing the collapsed loess cave is vertically connected to the vault. The relative position of the cylindrical body and tunnel is shown in Figure 25. In the course of collapsed loess cave development, the undisturbed structure of natural sedimentary loess is destroyed by immerging, thus the remolded loess in the cylindrical body is formed under the condition of moisture reducing after soaking. Compared with the undisturbed loess, the shear strength of the remolded loess decreases, and it has a significant influence on the safety of large-span tunnel excavation.

Settlement change of ground surface during tunnel excavation is as shown in Figure 26. When the tunnel excavation surface passes through the wet sinking loess cavern, the ground begins to settle significantly from the vault to the surface and the amount of settlement increases rapidly. When the working face goes across the collapsed loess cave until the end of model 


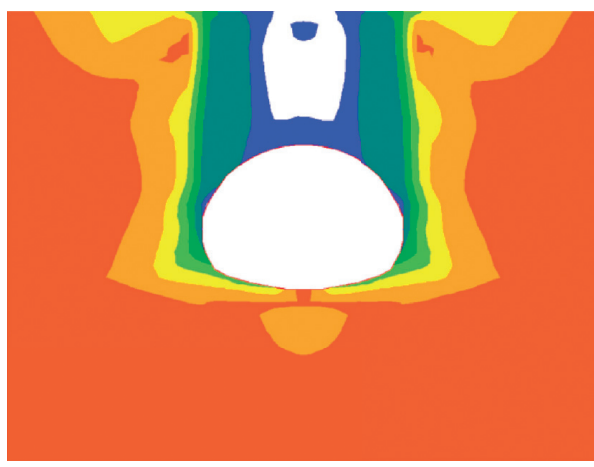

(a)

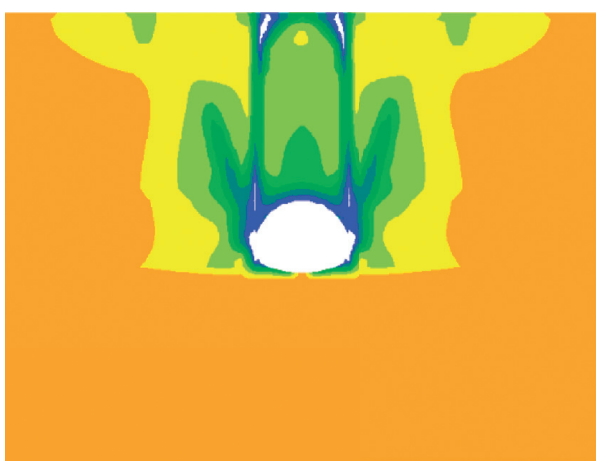

(c)

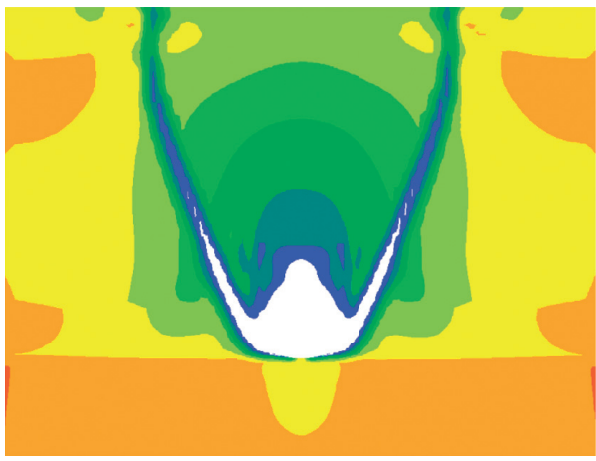

(e)

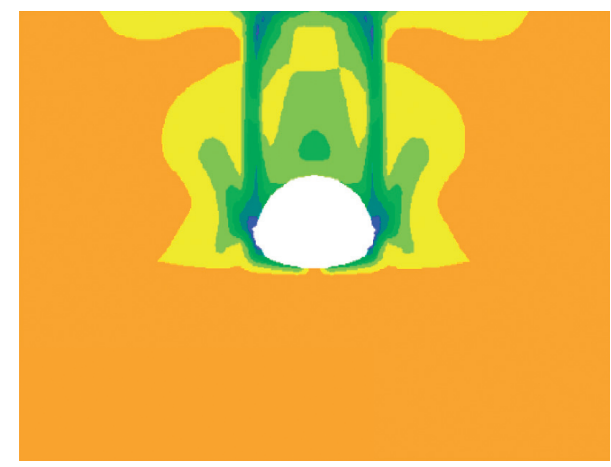

(b)

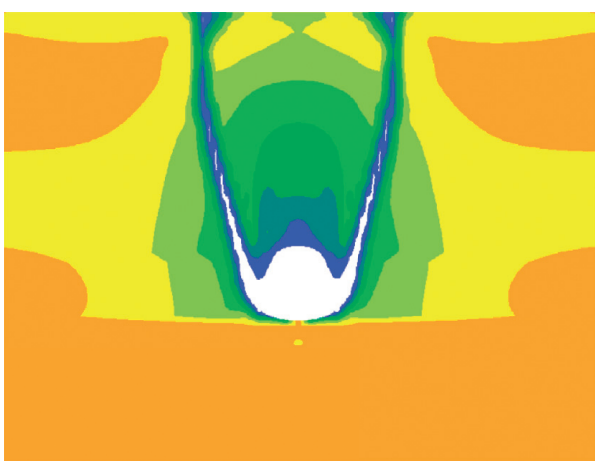

(d)

Zone extra 6

Magfac $=0.000 e+000$

Gradient calculation

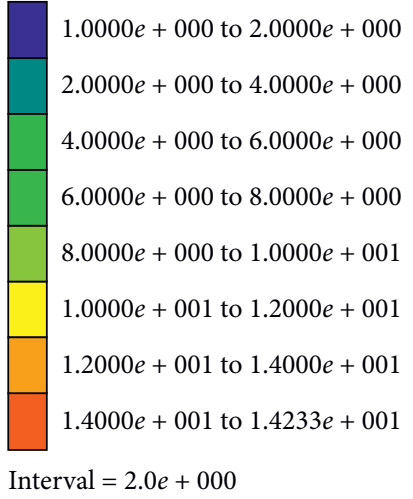

(f)

Figure 23: Distribution of structural damage after tunnel excavation. (a) Depth: $10 \mathrm{~m}$, (b) depth: $20 \mathrm{~m}$, (c) depth: $30 \mathrm{~m}$, (d) depth: $40 \mathrm{~m}$, (e) depth: $50 \mathrm{~m}$, and (f) generalized sensitivity.

tunnel excavation, the preliminary lining is not closed and the secondary lining support is unfinished, and deformation of collapsed loess cave and surrounding rock has not reached the convergence condition. Compared with the deformation of undisturbed loess, once the collapsed loess cave is disturbed by excavation, it will cause rapid settlement and deformation and lead to deformation destruction of the surrounding rock, resulting in vault collapse and other engineering accidents.

Figure 27 shows the stratum subsidence vector diagram that the tunnel goes across the collapsed loess cave. It can be seen that the form of collapsed loess cave failure is characterized by the overall settlement deformation failure in the process of large-span tunnel excavation, and the influence depth is large and the range is wide. For large-span loess tunnel, loess structural unit is damaged, pore collapses, and fabric suddenly changes with the development of deformation, with brittle failure characteristics; at the same time, the tunnel excavation will cause more intense disturbance to the soil column of the collapsed loess cave; thus, the soil structure of the collapsed loess cave is destroyed again, inducing the development of large deformation, so as to cause the destruction of undisturbed loess nearby and serious damage of the surrounding rock. The soil mass, which structure has been destroyed, acts on the preliminary lining structure, which requires increasing the bearing 


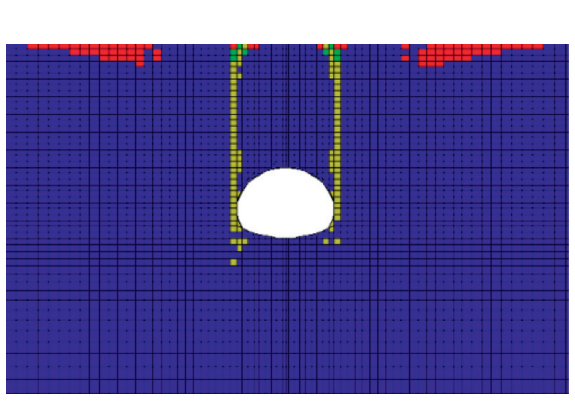

(a)

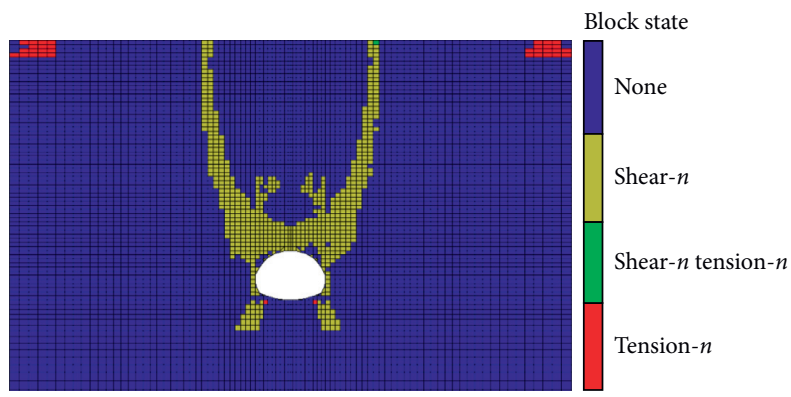

(c)

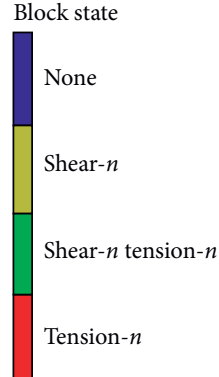

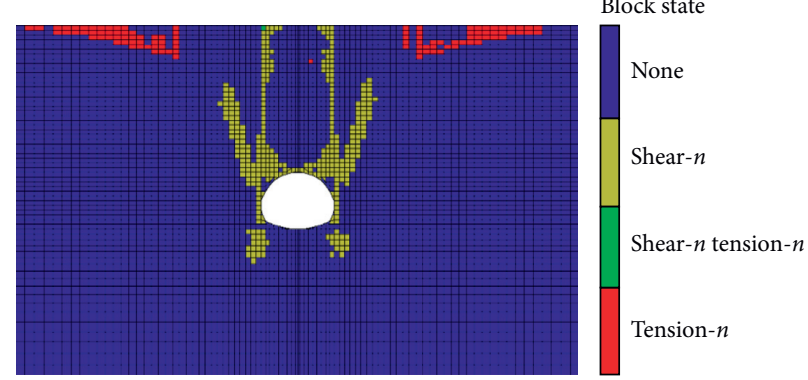

(b)

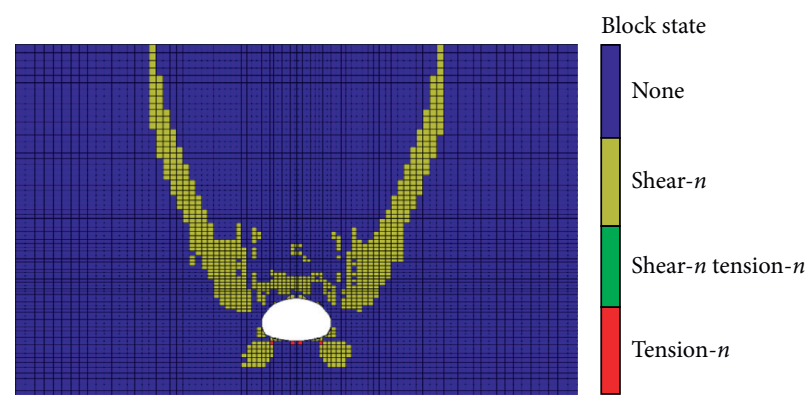

(d)

Figure 24: Distribution of plastic zone after tunnel excavation. (a) depth: $20 \mathrm{~m}$, (b) depth: $30 \mathrm{~m}$, (c) depth: $40 \mathrm{~m}$, and (d) depth: $50 \mathrm{~m}$.

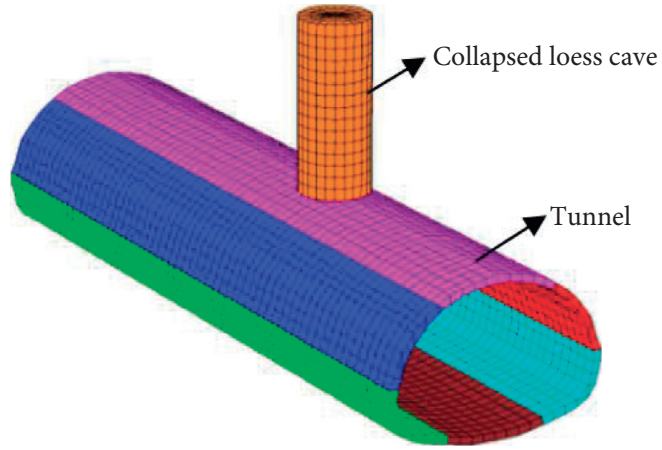

FiguRe 25: Diagrammatic sketch of collapsed loess cave and tunnel.

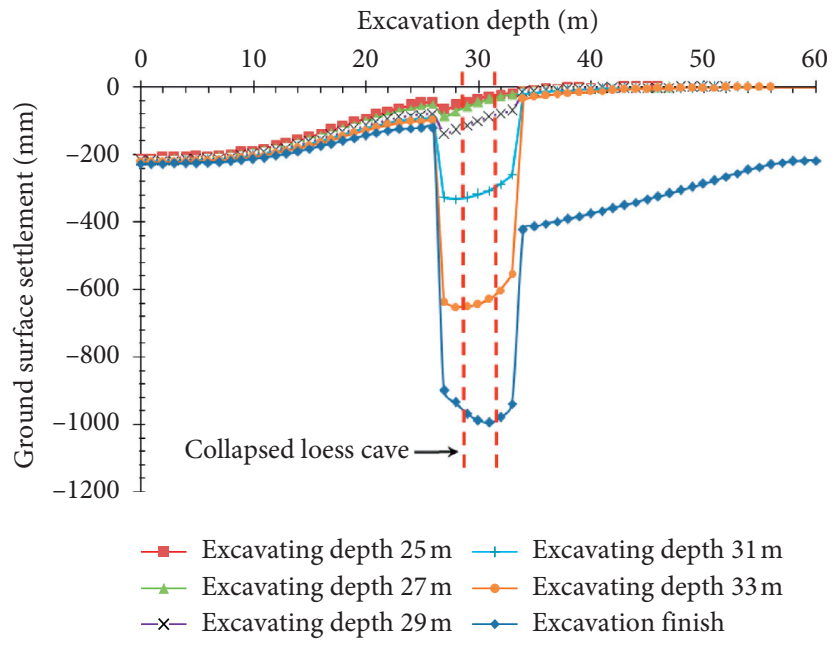

FIGURE 26: Ground settlement during passing through the collapsed loess cave. 


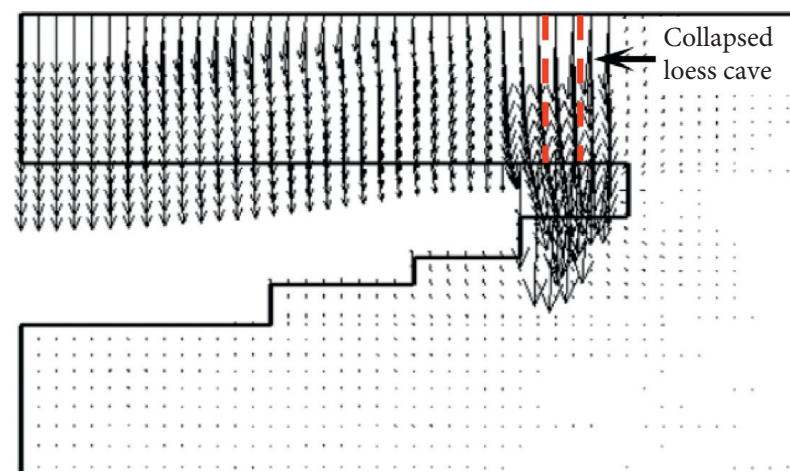

FIGURE 27: Vector diagram of settlement during passing through the collapsed loess cave.

capacity of the preliminary lining structure. When the preliminary lining structure loses its stability, the collapse failure of the surrounding rock will appear.

3.4. Analysis of Excavation Face Mud Flowing. When there is a high saturated degree area (liquid index is greater than 0.75) before a position of excavation face in model $\mathrm{A}$, the water content of the soil is greater than the liquid limit. With the excavating tunnel, the soil is in a state of flow when the structure of the soil in a high saturated degree area is damaged after being disturbed. With the development of plastic deformation in the process of excavation, generalized sensitivity of soil in high saturated degree area obviously decreases, and it causes the decreasing of soil cohesion.

Figure 28 shows the distribution curve of cross-sectional settlement deformation on the vault in a high saturated degree area when the depth of the tunnel is $10 \mathrm{~m}$. Before the tunnel face passes through the high saturated degree area, the development of ground subsidence is very small. When the working face lies just $5 \mathrm{~m}$ before the high saturated degree area, settlement and deformation of soil begins to increase, and the excavation face has brought disturbance to the soil in the high saturated degree area. When the excavation face gets to the high saturated degree zone, settlement of the vault soil extended to $3 \mathrm{~m}$ in the vertical direction. That is, the vault collapse occurred and the deformation of working face is very prominent in the horizontal direction, thus flowing plastic state soil on excavation face has appeared. The development of damage in the high saturation zone results from the combined effects of settlement deformation of the surrounding rock, shear deformation of the excavation face, flow from the excavation face, and collapse of the overburden on the vault.

When the excavated face reaches the high saturated degree zone, the plastic zone of the surrounding rock is shown in Figure 29. Under the action of construction disturbance, the soil structure in the high saturated degree area is destroyed. With the development of the soil plastic deformation, the excess hydrostatic pressure is produced, thus the effective stress and shear strength of soil decreases. Soils in areas of high saturation develop large shear plastic zones and deform towards the excavation face, causing failure of the face. At the same time, with the large deformation of excavation face soil mass, vault soil and excavation face lose support, and then

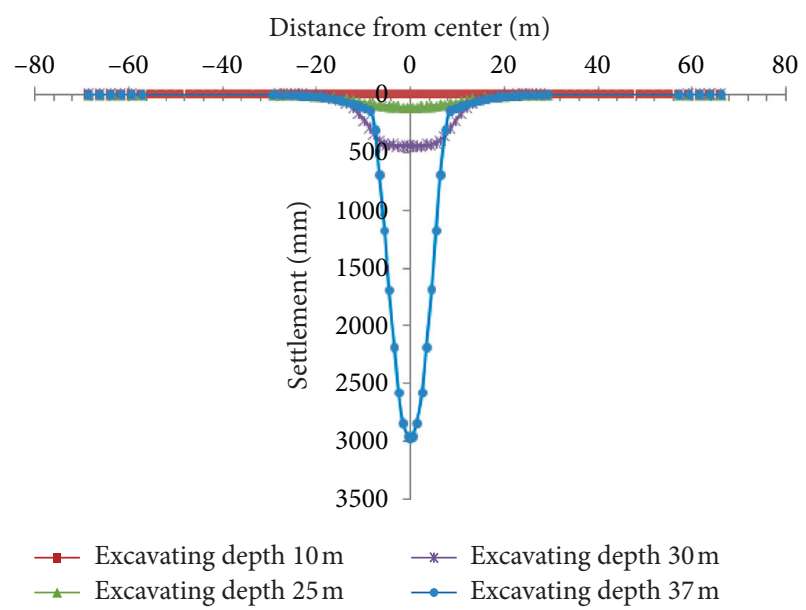

FIgUre 28: Tunnel vault settlement during excavation.

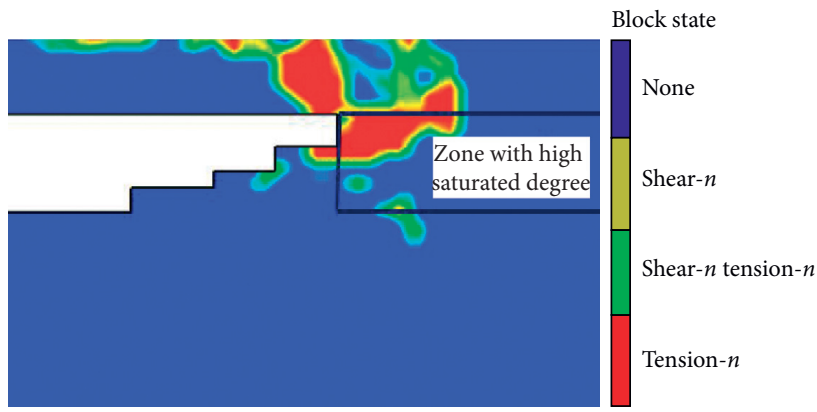

Figure 29: Distribution of plastic zone when excavation face arrives at the high saturated degree area.

collapse. Therefore, the soil damage flowing of excavation face is essentially the combined mechanical effect of the surrounding rock on the vault, and excavation face deformation failure in longitudinal and vertical directions.

3.5. Instability Evolution Analysis of Overlaying Slope. The model B with tunnel entrance, passing into a slope with slope ratio 1, is set up. According to simulation analysis of excavating and supporting, the generalized sensitivity and plastic area distribution diagram of soil slope can be obtained, as shown in Figures 30 and 31 . When the tunnel face is excavated up to $20 \mathrm{~m}$, the structure damage area and plastic zone of soil slope with tunnel entrance are revealed, respectively. It can be seen that the slope destruction of undisturbed loess develops from the arch shoulder to the top of the slope forming two shear zones. A large area around shear zones forms a tension plastic zone caused by traction tension, which is through the top of the slope. The area, generalized sensitivity attenuating to 1.0 , also develops from the vault to the top, and the scale of generalized sensitivity of soil attenuating at top expands to both sides of the tunnel. It is shown that the slope is subjected to shear, shear-tensile, and tensile action, resulting in the overall sliding shear failure of the slope and the collapse of the vault surface at the tunnel entrance. Therefore, due to the loess structure attenuation of the slope under shear and tension, the shear and 


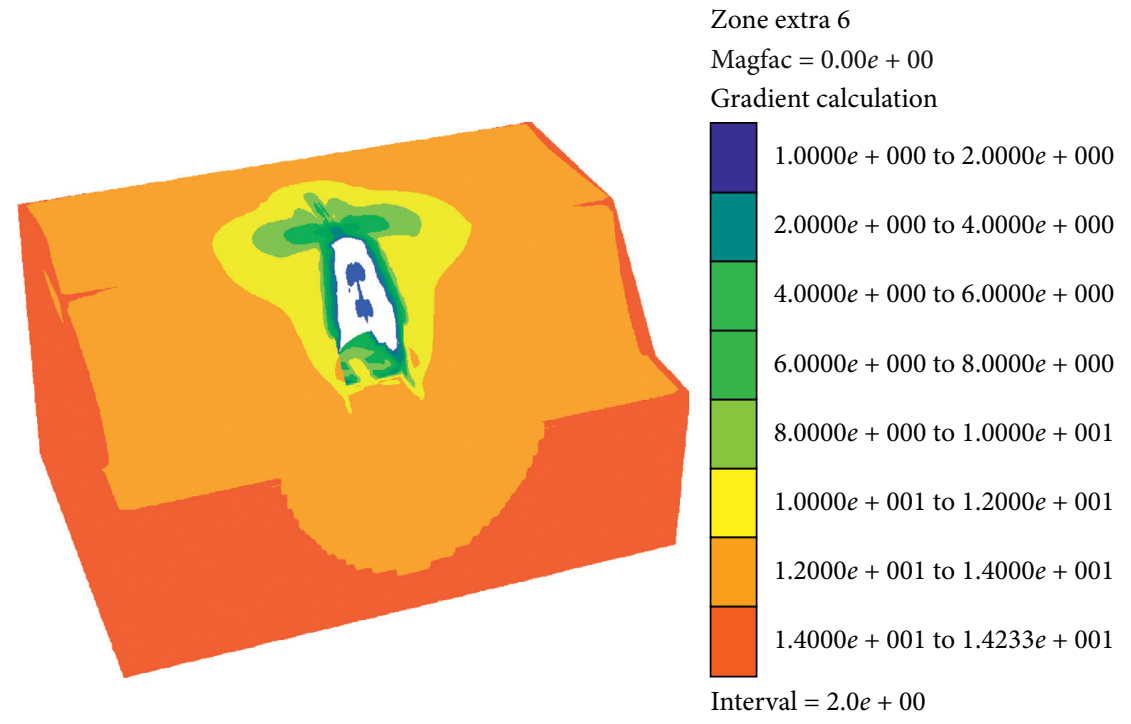

FIGURE 30: Distribution zone of generalization sensitivity of the overlaying slope.

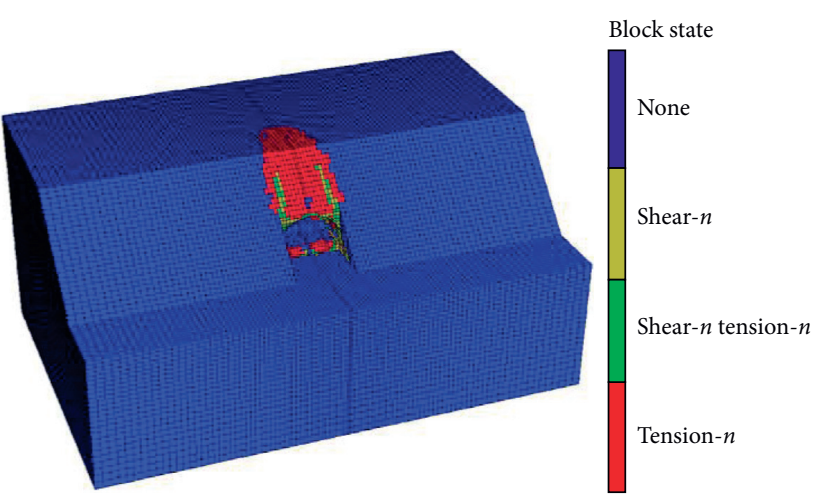

FIgURE 31: Plastic zone of the overlaying slope.

tensile strength of the soil decreases and eventually results in the tensile and shear instability of the slope.

\section{Conclusions}

(1) Loess tunnel safety is influenced by the loess mechanical properties of surrounding rocks such as structural property, collapsibility, watering sensitivity, erosion resistance, and the adverse geological conditions of collapsed loess cave, immerging collapse, fissures, landslide, and others. Large deformation, landslide, tunnel lining cracking, and other failures often occur in the process of loess tunneling. The main influence factors of loess tunnel destruction include soil structure failure and plastic deformation under moistening and loading closely related to loess structural property, loess damage of water immerging, which is closely related to adverse geological conditions such as hidden holes, fissures, landslides, and mud flowing, and surrounding rock relaxation and supporting effect are closely related to tunnel excavation and lining support. The types of loess geological hazards caused by tunnel excavation are summarized.

(2) The natural loess structure is disturbed by shear deformation of excavation face and the surrounding rock in the process of construction of the loess tunnel. With the structure destruction of dry loose loess and saturated loose loess, dry soil particle and mud flowing occur in the tunnel face, respectively. The surrounding rock of shallow buried loess tunnel is prone to large-area collapse or vault collapsing, accompanied by soil structure damage and the development of shear deformation zone. The slope unloading fissures under hydraulic erosion and hidden holes under loess collapsing are developed on the overlying slope, which is prone to landslides under the additional disturbance of the entrance tunnel.

(3) The Mohr-Coulomb elasto-plastic constitutive model of loess, the structural index changing with plastic deformation, is applied to reveal the shear failure and fracture development of overlying soils strata caused by tunnel arch settlement. The characteristics of structural index distribution of loess surrounding tunnel are determined. The deformation characteristics of roof falling, tunnel excavation face flowing, and overlying soil collapse are revealed in loess tunnel.

(4) The structure damage and shear deformation of loess with large void ratio and strong structural property increase due to excavation and support of tunneling. Along with the soil structural attenuation and evolution of strength-deformation characteristics, shear zones are easy to occur in surrounding rocks of shallow tunnels where the arch shoulder develops vertically and that of deep tunnels where the arch shoulder develops outward and through the ground, increasing the pressure of the lining structure. In the 
construction of the loess tunnel, the principles, including of short excavation, little disturbance, and strong support, should be followed to reduce the disturbance of loess of the tunnel surrounding rock and restrain the plastic deformation development of the surrounding rock, structural attenuation, and shear band development.

(5) According to the phenomenon of dry soil and mudflow caused by the action of soil and water, the initial lining cracking and structural damage to the supporting envelope and surrounding rock after loess shear failure, the reinforcement of the excavation face should be carried out in advance to avoid the failure caused by the slippage of the supporting face.

(6) The strong structural property, strong collapsibility, and complicated landform of loess are the basis of unfavorable geological conditions development. According to the engineering properties of loess, evaluation on formation possibility of adverse geological conditions, reasonable determination of surrounding rock grade of tunnel, the buried depth state, as well as anti-disturbance measurements of excavation and lining support can effectively avoid the loess tunnel failures.

\section{Data Availability}

The data used to support the findings of this study are available from the corresponding author upon request. Requests for data, 12 months after publication of this article, will be considered by the corresponding author.

\section{Conflicts of Interest}

The authors declare that they have no conflicts of interest.

\section{Acknowledgments}

The authors are grateful for the financial support by the National Natural Science Foundation of China under Grant nos. 41272320 and 11572245 .

\section{References}

[1] S. J. Shao, L. Q. Wang, S. Shao, and Q. Wang, "Structural yield and collapse deformation of loess," Chinese Journal of Geotechnical Engineering, vol. 39, no. 8, pp. 1-9, 2017.

[2] B.-P. Wen and Y.-J. Yan, "Influence of structure on shear characteristics of the unsaturated loess in Lanzhou, China," Engineering Geology, vol. 168, pp. 46-58, 2014.

[3] F. Tonon, "ADECO full-face tunnel excavation of two $260 \mathrm{~m} 2$ tubes in clays with sub-horizontal jet-grouting under minimal urban cover," Tunnelling and Underground Space Technology, vol. 26, no. 2, pp. 253-266, 2011.

[4] A. Graziani and D. Boldini, "Remarks on axisymmetric modeling of deep tunnels in argillaceous formations," Tunnelling and Underground Space Technology, vol. 28, pp. 70-79, 2012.
[5] C. W. W. Ng, Y. Hong, G. B. Liu, and T. Liu, "Ground deformations and soil-structure interaction of a multi-propped excavation in Shanghai soft clays," Géotechnique, vol. 62, no. 10, pp. 907-921, 2012.

[6] A. Lisjak, B. Garitte, and G. Grasselli, "The excavation of a circular tunnel in a bedded argillaceous rock (Opalinus Clay): short-term rock mass response and FDEM numerical analysis," Tunnelling and Underground Space Technology, vol. 45, pp. 227-248, 2012.

[7] A. M. Assallay, C. D. F. Rogers, and I. J. Smalley, "Formation and collapse of metastable particle packings and open structures in loess deposits," Engineering Geology, vol. 48, no. 1-2, pp. 101-115, 1997.

[8] A. M. Vietor, C. D. F. Rogers, and I. J. Smalley, "Formation and collapse of metastable particle packings and open structures in loess deposits," Engineering Geology, vol. 48, no. 1-2, pp. 101-115, 1997.

[9] S. J. Shao, C. M. Yang, Y. Y. Jiao et al., "Engineering properties of collapsible loess tunnel," Chinese Journal of Geotechnical Engineering, vol. 35, no. 9, pp. 1580-1590, 2013.

[10] B. Baudet and S. Stallebrass, "A constitutive model for structured clays," Géotechnique, vol. 54, no. 4, pp. 269-278, 2004.

[11] S. Shao, Q. Wang, and W. Zheng, "Generalized sensitivity for unsaturated cohesive soils," Unsaturated Soils: Research \& Applications, vol. 2, pp. 1329-1334, 2014.

[12] FLAC3D, User Manual, ItascaConsulting Group, Minneapolis, MN, USA, 2015. 